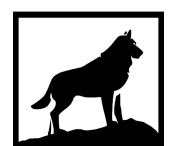

Michigan

Technological

1 8 8 5 University
Michigan Technological University

Digital Commons @ Michigan Tech

DESIGN AND DEVELOPMENT OF PERSONAL PROTECTIVE EQUIPMENT PRODUCTS TO REDUCE THE IMPACTS OF MACHETE INJURIES FOR INDIGENOUS NGÄBE SUBSISTENCE FARMERS IN BOCAS DEL TORO, PANAMA

Micah Koller

Michigan Technological University, mrkoller@mtu.edu

Copyright 2019 Micah Koller

Recommended Citation

Koller, Micah, "DESIGN AND DEVELOPMENT OF PERSONAL PROTECTIVE EQUIPMENT PRODUCTS TO REDUCE THE IMPACTS OF MACHETE INJURIES FOR INDIGENOUS NGÄBE SUBSISTENCE FARMERS IN BOCAS DEL TORO, PANAMA", Open Access Master's Report, Michigan Technological University, 2019. https://doi.org/10.37099/mtu.dc.etdr/938

Follow this and additional works at: https://digitalcommons.mtu.edu/etdr

Part of the Other Mechanical Engineering Commons 


\title{
DESIGN AND DEVELOPMENT OF PERSONAL PROTECTIVE EQUIPMENT PRODUCTS TO REDUCE THE IMPACTS OF MACHETE INJURIES FOR INDIGENOUS NGÄBE SUBSISTENCE FARMERS IN BOCAS DEL TORO, PANAMA
}

\section{By}

Micah R. Koller

\begin{abstract}
A REPORT
Submitted in partial fulfillment of the requirements for the degree of MASTER OF SCIENCE

In Mechanical Engineering
\end{abstract}

MICHIGAN TECHNOLOGICAL UNIVERSITY

2019

(c) 2019 Micah R. Koller 
This report has been approved in partial fulfillment of the requirements for the Degree of MASTER OF SCIENCE in Mechanical Engineering.

Department of Mechanical Engineering - Engineering Mechanics

\author{
Report Co-Advisor: Dr. Craig Friedrich \\ Report Co-Advisor: Dr. Kari Henquinet \\ Committee Member: Dr. David Watkins \\ Department Chair: Dr. William Predebon
}


For Norma Sanchez 


\section{Table of Contents}

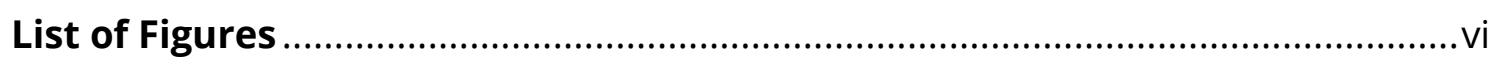

Acknowledgements.............................................................................................

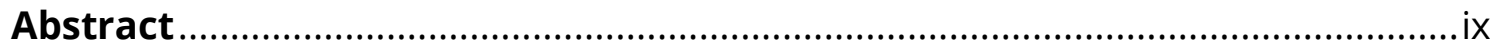

Chapter 1 The History and Criticisms of Design for the Poor ............................ 1

1.1 Appropriate Technology ........................................................................

1.2 The Bottom of the Pyramid .....................................................................

1.3 Criticisms of Bottom of the Pyramid Economics ........................................2

1.4 A New Generation of BoP Economics..........................................................

1.5 The Role of a Mechanical Engineer ...............................................................4

Chapter 2 Review of the Participatory Design Process ........................................ 5

2.1 Participatory Design: Frameworks ...............................................................5

2.2 The Importance of Understanding Local Context .....................................

2.3 Co-creation, Co-design, and Co-Development........................................... 8

Chapter $\mathbf{3}$ Local Context and the Machete Injury Problem.................................11

3.1 Quebrada Plátano, Bocas del Toro: History, Culture, and Economics.......11

3.2 The Tool that Makes Life Possible.............................................................18

3.3 Machete Accidents and Injuries: A Dangerous Fact of Life .........................21

3.4 Machete Injuries: A Problem Worth Solving ..............................................23

3.5 Household Interviews in Quebrada Plátano .................................................24

3.5.1 Purpose of Household Interviews...............................................24

3.5.2 Interviewing Methods .................................................................26

3.5.3 Interview Results: Realities and Perceptions of the Problem .....29

Chapter 4: Machete PPE Product Designs Come into Focus..................................32

4.1 Analysis of Key Product Attributes.............................................................32

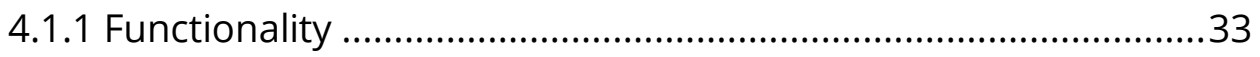

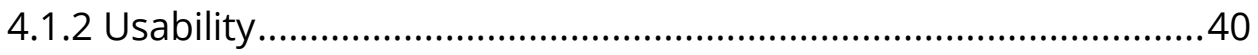

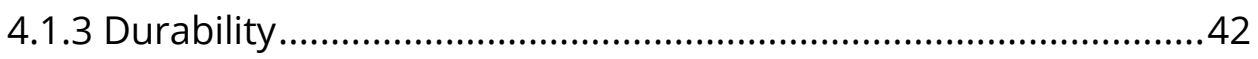




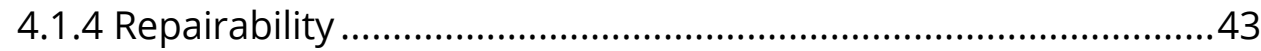

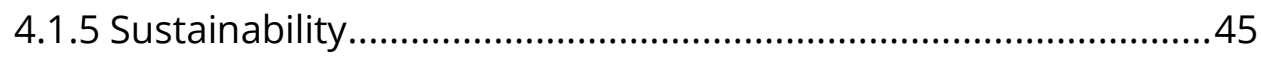

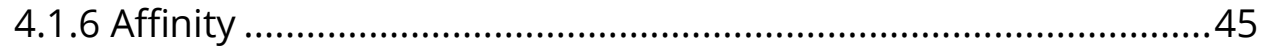

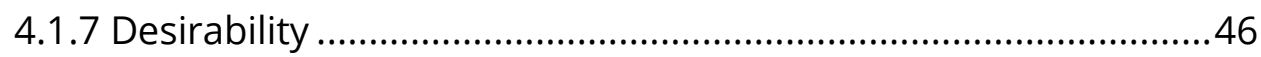

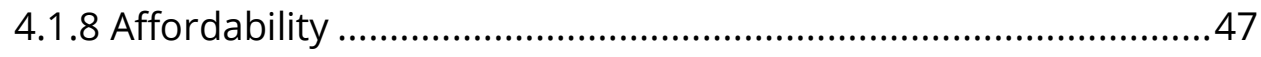

4.2 Summary of Key MPPE Product Design Requirements..............................47

Chapter 5: Viable Business Model Considerations for MPPE ...............................49

5.1 Business Models in the BoP Context ........................................................49

5.2 Affordability and Price Considerations ......................................................52

5.3 Marketing and Advertising........................................................................54

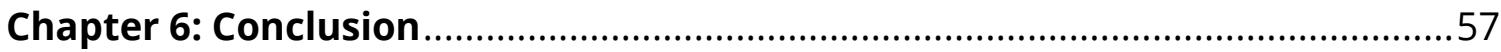

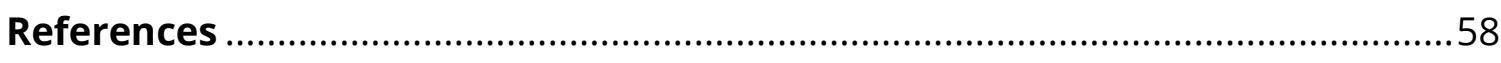

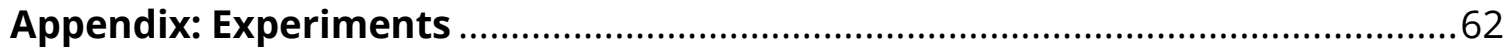

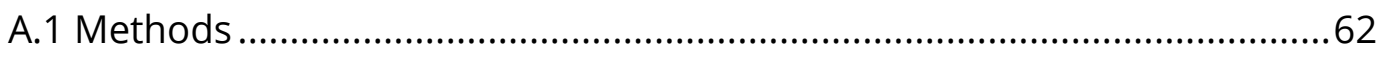

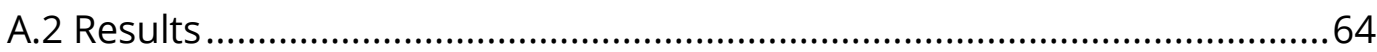




\section{List of Figures}

Figure 3.1.1: Map of Panama and Bocas del Toro ...................................................12

Figure 3.1.2: Entrance to the community of Quebrada Plátano ....................................13

Figure 3.1.3: Aerial photograph of Quebrada Plátano .................................................. 15

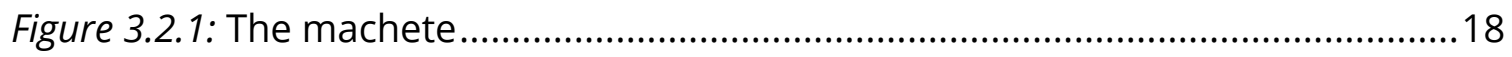

Figure 3.2.2: Examples of machete use ................................................................19

Figure 3.2.3: Clearing land with machetes..................................................................20

Figure 3.3.1: Muddy access footpath to Quebrada Plátano..........................................23

Figure 4.1.1.1: ASTM F2992-15 cut resistance test protocol ...........................................36

Figure 4.1.1.2: Commercially available cut and impact resistant work glove ...............38

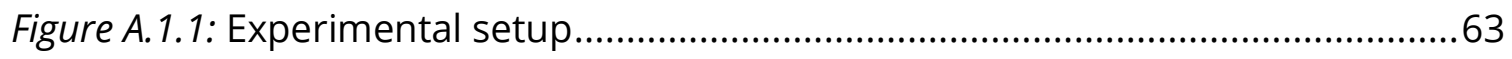

Figure A.2.1: Result of woven Kevlar fabric sample in perpendicular impact test......66 


\section{Acknowledgements}

This report is the ultimate product of a four year journey that began in late 2015 with the enthusiasm of Dr. John Gershenson who persuaded me to join the PCMI program at Michigan Tech where I made lifelong friendships with energetic students who like me, were ready and willing to put themselves through untold hardships in order to make a difference in the world and transform lives, including their own.

In Panama, I was nurtured and supported by a hardworking and committed team of Peace Corps staff who never wavered in their commitment to better the lives of Panamanians living in poverty. Thanks to Arcadio Aguilar for taking me under his wing and for his charismatic lessons that developed my crucial ability to communicate. To our medical doctors -- true heroes who work tirelessly to keep us all alive and healthy, and who I could always count on as my lifeline. To my Peace Corps Panama brothers and sisters, we are forever bonded by this experience that few others can understand. To Ian McGuire whose intellectual curiosity helped transform my perspectives about life and helped me through so many difficult moments. To Ire Burgoa whose enormous, open heart deeply affects all those around her, and whose impressive knowledge and tireless work ethic inspired me to keep on struggling for two years.

The people of Quebrada Plátano probably have no idea the profound impact simply letting me into their everyday lives had on my own. Living amongst those who are perpetually on the cusp of disaster yet remain resilient and proud helped me understand what really matters. Thanks so much for the countless meals I enjoyed from the products of your hard labor, and all the conversations and friendship we shared. Eternal gratitude to my adopted family who graciously took me in, cared for me, and put up with my absolute ineptitude with just the right level of playful derision. I humbly express my admiration for Gregorio Abrego who despite the 
struggles of poverty and lack of formal education, dedicates himself thanklessly, day in and day out, physically and mentally, to the betterment of his entire community. He is the inspiration that will guide me for the rest of my years.

Thanks to my advisors and committee members at Michigan Tech who supported me throughout this project. Dr. David Watkins' commitment to serving the rural people of Panama led him to experience first-hand the hardships people face in Quebrada Plátano. Dr. Kari Henquinet's experience in social science and international development proved invaluable while I developed the project. Dr. Craig Friedrich supported my ideas from the outset and provided materials that made it possible. Finally, I must thank Dr. Blair Orr, whose wisdom and lessons gave me perspective that carried me through the difficult periods during my Peace Corps service.

Finally, a big thanks to my family for their unfaltering support of my crazy plans and willingness to visit me and experience life in Quebrada Plátano. Those visits meant a lot to me. 


\begin{abstract}
Design and development of personal protective equipment products for workers using machetes (MPPE) is considered in the specific context of indigenous Ngäbe subsistence farmers in a small, rural community in Bocas del Toro, Panama where the author spent two years as a Peace Corps volunteer from 2017-2019. People in this community regularly suffer significant health and economic impacts due to accidents with machetes, which are essential tools in their farm work and daily lives. The history, criticisms, and recent frameworks related to product design and development in resource-poor markets is examined, and specific details of the problem of machete injuries within the local context are described using the author's personal experiences and a series of household interviews. This information is used as a framework to develop design considerations and requirements, and strategies for effective, sustainable product implementation and business model development. Ideas for specific MPPE products like protective socks and gloves made from high-tech, cut- and impact-resistant materials are presented, as well as business model suggestions that involve local manufacturing, distribution, and marketing.
\end{abstract}





\section{Chapter 1. The History and Criticisms of Design for the Poor}

\subsection{Appropriate Technology}

Engineers have taken interest in efforts to improve the living conditions of the world's poor for decades, starting with the appropriate technology (AT) movement inspired by the work of economist E.F. Schumacher in the 1960s. This movement aimed to help those living in poverty gain access to the most basic human needs of food, water, clothing, healthcare, sanitation, and education through the deployment of culturally appropriate, sustainable technology that would enlist local labor and utilize local resources (Dunn, 1978). The philosophy of AT is that the solution to poverty lies within the technology itself -- that if designed perfectly and with consideration for hyper-local needs, it would allow people to work themselves out of poverty or at least to become self-sufficient enough that their position at the bottom of the economic ladder would become less burdensome. To this end, many creative, highly practical, and sustainable technologies have been invented by engineers (Dunn, 1978). AT projects often viewed the world's poor as having no place in the mainstream consumer economy enjoyed by wealthier people, and projects often relied on outside capital investments that failed to become economically viable in the long-term (Polak, 2008). Worse yet, some projects had unintended consequences that disturbed existing local economic structures, further perpetuating the poverty they attempted to solve (Dunn, 1978).

\subsection{The Bottom of the Pyramid}

At the turn of the century, examples of the failures of the AT approach and the naivety of the idea that the multifaceted problem of poverty could be solved primarily through technological solutions alone had become increasingly apparent. Economists C.K. Prahalad and Stuart Hart developed a new philosophy of design for 
the Bottom of the Pyramid (BoP), with the idea that the bottom two thirds of the world's population by income could be a vast untapped source of fortune for entrepreneurs and businesses who are willing to seek it; and that the world's poor should be viewed as potentially active members of the mainstream consumer economy, if only products could be designed and marketed specifically for their unique needs (Prahalad \& Hart, 2002). These efforts could be led by non-profit organizations, small-scale social enterprises, or even large multinational corporations (Ben Letaifa \& Reynoso, 2015). Solutions to poverty require viable, sustainable business models, in addition to well-designed and practical technology (Prahalad \& Hart, 2002).

\subsection{Criticisms of Bottom of the Pyramid Economics}

The BoP philosophy has been criticized in that it could fail to satisfy poor consumers' most basic needs, or to increase their overall wellbeing -- that it is simply a form of globalization that encourages exploitation of the poor by multinational corporations marketing fashionable products they don't really need, and leaving them with even less resources to meet their basic needs for nutrition, education, and healthcare (Jaiswal, 2008). This is supported by evidence that people engage in conspicuous consumption even if their basic needs are not yet satisfied (van Kempen, 2005). The poorest consumers could also be excluded from certain essential products like medicines if companies assume they cannot afford them (Jaiswal, 2008). Whether sustainable business models can be created based on solutions for the world's poorest -- people living on less than $\$ 2$ per day -- is questionable, especially within the confines of large corporate structures accustomed to working in wealthy markets (Polak, 2008). Other factors make these business operations even more difficult, such as corruption, lack of regulation, and lack of basic infrastructure that characterize many countries in which the poor live (Jaiswal, 2008). For these reasons, it is essential that any BoP project is able to demonstrate a measurable impact on 
reducing poverty and meeting people's most basic needs (Jaiswal, 2008; Polak, 2008). Business models need to ensure affordability, ideally for people living on less than $\$ 1$ per day, demonstrate viability and profitability within a short time frame acceptable to investors, and have a capacity to scale up in order to reach millions of consumers (Polak, 2008).

\subsection{A New Generation of BoP Economics}

The BoP philosophy has continued to evolve in order to address these concerns, and strategies have been developed to ensure real impacts on poverty reduction and the development of viable, sustainable business models. Rather than see the poor as passive consumers (Ben Letaifa \& Reynoso, 2015), newer approaches view those in the target market in a more participatory, active role in the co-design and co-creation of products, and the co-development and co-management of business ventures, ensuring local cultural suitability and expanding the local entrepreneurial capacity (Simanis \& Hart, 2008). It has been demonstrated that local people can have more altruistic motives during the design process than outside profit seekers (Pansera \& Sarkar, 2016), so their participation helps ensure the venture will have positive social impact. Several frameworks have been developed which detail the best practices for the co-design and co-venturing processes (Castillo, Diehl, \& Brezet, 2012; IDEO, 2015; Mattson \& Wood, 2014; Simanis \& Hart, 2008). Most recently, there is an emphasis on the development of product-service business models (Ceschin \& Gaziulusoy, 2016) in which services are tied together with technological solutions in order to empower local entrepreneurship and provide for basic needs that sales of a product alone often cannot meet (Ben Letaifa \& Reynoso, 2015). 


\subsection{The Role of a Mechanical Engineer}

The last five decades since engineers first began to design products to alleviate poverty have repeatedly illuminated the importance of gaining a careful, intimate understanding of the local context in which those products will be used. Though mechanical engineers are well trained in mechanical design, optimization, and manufacturing techniques, all essential to produce effective solutions (Mattson \& Wood, 2014), it is essential that they broaden their horizons and embrace fields like anthropology, sociology, economics, management, and marketing, learning to work within interdisciplinary teams to tackle the multifaceted nature of poverty and its social, political, technical, ecological, and economic factors. They need to understand the entire process: from identification of new opportunities, to product design, to business implementation (Mattson \& Wood, 2014). To work in this field, they need to recognize and let go of their assumptions based on the familiar context of western, developed product markets, and focus on the true needs of the poor people with whom they are designing solutions (Mattson \& Wood, 2014). 


\section{Chapter 2. Review of the Participatory Design Process}

\subsection{Participatory Design: Frameworks}

Solutions for BoP markets require evolutionary or revolutionary strategies that start from the ground up, not simply incremental modification of existing products designed for wealthy markets with packaging redesigns, reduction of durability, or reassessment of cost and price schemes (Castillo et al., 2012). In the past two decades, an emerging field has begun to develop and test new strategies to design products and services that people in BoP markets would reliably pay for and use to help meet their basic needs, and that can measurably reduce poverty not only through the use of the product or service itself, but also through the activities of a sustainable business venture. Many academics and institutions have attempted to distill this process into generalized frameworks or a series of concrete steps designed to maximize the potential for success. Jagtap et al. (2015) states that the main ingredients of the design process are first to determine the problems and requirements of the target market, come up with potential solutions, gather more information, and finally develop a strategy for implementation. Throughout the process, requirements and solutions co-evolve as designers repeatedly propose tentative solutions that enhance their understanding of the originally understood requirements. In a similar way, the Human Centered Design (HCD) Toolkit, first published by the design and consulting firm IDEO in 2009, emphasizes constant experimentation and prototyping while working within diverse interdisciplinary teams alongside the eventual beneficiaries of the product or service. The main components of the HCD process are inspiration, ideation, and implementation, each carried out with outside designers and professionals on equal footing with local BoP people (IDEO, 2015). Castillo et al. (2012) define the design process as first determining factors of desirability, developing technical aspects for feasibility, 
figuring out economic viability, and assessing sustainability. After analyzing several different existing frameworks, Castillo et al. (2012) propose a more straightforward 5-stage process to guide designers:

(1) Preparation: Defining team members, community partners, design objectives and strategies, time schedules and space required to complete the project.

(2) Contextualization: Through the use of extensive qualitative research methods, the team develops deep empathy for the people they are designing for. Research is initially generative, inspiring imagination about new opportunities. Later, methods can become evaluative, to quickly learn about people's response to proposed solutions.

(3) Concept development: As a result of a co-creation process, the team will select the most promising ideas, and detail design concepts. Collected data starts to define possible product and service opportunities, as well as prototyping, testing, and evaluating initial solutions.

(4) Implementation: Use of various business and management research strategies, small-scale tests, and continued action learning to begin developing a viable, sustainable business model

(5) Managing: Before a solution is delivered to the market, it is important to foresee its post-consumption aspects. In the case of a service-oriented solution, it is necessary to define the distribution system and monitoring of the service in the long term. For product-oriented solutions, it is necessary to plan for maintenance of the product as well as life-cycle analysis to maximize sustainability.

Mattson \& Wood (2014) emphasize the need to begin any project by forming meaningful relationships, and to choose a project with community involvement with carefully selected local team members willing to be mentored and take over from outsiders once the project is fully implemented. Success criteria should be clearly defined from the outset with community approval as a primary objective, and with measurable reduction of poverty the overarching goal. 


\subsection{The Importance of Understanding Local Context}

People in BoP markets generally have very different problems, circumstances, values, and design requirements from those in high-income markets. A lack of information about what people need, what capabilities they can offer, and what barriers they face often leads to failure of projects in BoP markets (Ceschin \& Gaziulusoy, 2016). Product designs in the developing world usually do not fail because of the mechanics of the generic solution finding process, but because of a weak understanding of the context (Mattson \& Wood, 2014). In fact, all of the nine principles for successful product design in developing countries laid out by Mattson \& Wood (2014) fundamentally relate to the context of the problem and solution, rather than technical soundness. Any team dedicated to the design of solutions to reduce poverty in the developing world needs to focus on context in order to uncover all the subtle details that will inevitably affect the needs, desires and values of their target market, and the barriers to acceptance, implementation, and sustainability of the product, service, or business venture. Outsiders, especially engineers, need to learn to let go of assumptions and listen to what the community actually wants in order to be effective (Mattson \& Wood, 2014).

Understanding cultural context is most vital, as underlying values and cultural themes may lead people to accept or reject certain solutions (van Kempen, 2005), and may not be obviously apparent to outsiders. Value is inherently socially defined and differs from one context to another (Ben Letaifa \& Reynoso, 2015). For example, contrary to conventional thinking, it has been demonstrated that resource-poor people frequently engage in conspicuous consumption to boost their social status even if that hinders their ability to meet their more basic needs (van Kempen, 2005). In other words, social status itself could be considered a basic human need. Furthermore, certain groups of people like racial and ethnic minorities may be more likely to engage in this type of consumption as a means to compensate for their 
marginalized social status, but this depends strongly on the specific cultural values and historical context of these groups (van Kempen, 2005). Designers and engineers do not always heed these warnings; for example, there is often a tendency not to pay enough attention to requirements regarding aesthetics and ergonomics, leading to project failures in BoP markets (Jagtap et al., 2015), and there is often a great difficulty for outsiders to face the challenge of overcoming, or simply accepting cultural norms (Mattson \& Wood, 2014).

A detailed understanding of the daily lifestyle and practices is essential in understanding how easily new solutions could be incorporated into everyday lives. For example, a home construction enterprise for poor families in Latin America initially failed due to the passive role of customers that led to an underestimation of the importance of insights from daily practices and routines (Ben Letaifa \& Reynoso, 2015). Designers and entrepreneurs must also understand the unique barriers that exist in BoP markets like underdeveloped regulatory environments, inadequate infrastructure, limited literacy, education, and skills, and a high barrier to get access to credit (Ceschin \& Gaziulusoy, 2016). Urban and rural contexts involve distinct sets of barriers (Mattson \& Wood, 2014). Fully understanding existing local power structures and developing relationships with local and government influencers is also essential for the implementation of any solution (Mattson \& Wood, 2014).

\subsection{Co-creation, Co-design, and Co-Development}

The importance of working alongside local people and future beneficiaries from the beginning of the co-imagination and co-design processes through coimplementation and co-business management phases cannot be overstated. It is an

underpinning requirement for a comprehensive design process, where community members identify the challenges they face as well as the resources they have to address them, creating a deep sense of community bonding and cohesion that 
helps to envision solutions that are truly responsive to local needs (Castillo et al., 2012). According to Mattson \& Wood (2014), co-design encourages designer empathy, understanding of people's needs, and of the setting and environment. It promotes user sense of ownership, not just of the final product itself but of the entire process, helping to ensure viability and sustainability, and empowers resource poor individuals with a new understanding of the iterative nature of mechanical design and importance of prototyping for future product development and entrepreneurial activities. As users are encouraged to participate as team members in co-creation, the outside designer's role is transformed from problem solver to design thinking facilitator, giving support and guiding the diverse, multidisciplinary team through the process of finding the most suitable solution (Castillo et al., 2012). Moreover, resource-poor individuals on the design team offer unique insights and talents, having the advantage of experience in extremely resource-limited environments. Even with a lack of any formal education, they often have an intuition and ability to come up with more appropriate ideas and solutions than engineers accustomed to ample resources, with a better understanding of how to best utilize locally available materials, parts, technologies, and skills (Pansera \& Sarkar, 2016).

This idea is supported by my personal experience: an indigenous farmer in Panama with no formal education, faced with the seemingly hopeless situation of attempting to build a new pipe crossing for an aqueduct system without the benefit of expensive steel cable, suddenly remembered a long-discarded roll of chain link fencing material nearby, and began to tediously unravel and untangle the steel wires, eventually twisting them into a new steel cable that, to my surprise, became perfectly suitable and appropriate for the task at hand. This process of "frugal innovation" enables the combination of pre-existing technology with the capacity of the innovators to understand--or to "sense"--the surrounding context (Pansera \& Sarkar, 2016). Additionally, local innovators often have more altruistic motives and 
are driven to consider the social impacts that affect them, their families, and their neighbors in ways that outsiders could not imagine. They will also be motivated to involve people from diverse backgrounds being familiar with the special skills and knowledge they possess (Pansera \& Sarkar, 2016). Finally, it is critical that the codesign process not become exploitative, and that the ideas and intellectual property of local people are respected in the same way as in any other project, avoiding potential future conflicts that could jeopardize local trust, and ultimately, the entire project (Mattson \& Wood, 2014). 


\section{Chapter 3. Local Context and the Machete Injury Problem}

\subsection{Quebrada Plátano, Bocas del Toro: History, Culture, and Economics}

As a mechanical engineer, in order to gain insights into the product and business development process for impoverished consumers, I spent two years living and working with indigenous Ngäbe subsistence farmers in a small community in the Bocas del Toro region of Panama called Quebrada Plátano as a Peace Corps volunteer. In this capacity as the only outsider in the community, I was in a unique position to develop deep ties with community members, and a profound understanding of the culture, social structures, and problems people face. Initially this process was my primary goal, and it was only after 18 months of developing this deep understanding of the local context and people that I fully recognized an opportunity to develop personal protective equipment to reduce the impacts of machete injuries.

Panama is a small Central American nation with a population of just over 4 million (INEC, 2019). Its GDP per capita of $\$ 25,508$ (PPP) is the highest in Latin America and in the top third of all nations (World Bank, 2018), and it has enjoyed one of the highest economic growth rates in the region in the recent years (IMF, 2019). However, most wealth is concentrated in the capital city due to the importance of the Panama Canal and prominence of its financial industry, and the country is ranked 15th in the world for income inequality (World Bank, 2017). Rural areas outside the capital, where $35 \%$ of the population reside (INEC, 2010), often lack basic infrastructure such as potable water, sanitation, electricity, road access, basic health services, and educational facilities. This inequality falls disproportionately on Panama's 8 recognized indigenous groups which make up 12\% of the population (INEC, 2010). The Ngäbe are the largest indigenous group in Panama, whose 
population is concentrated in the western part of the country, from the mountainous, subtropical regions of Chiriquí on the Pacific side to the lowland, tropical Bocas del Toro region of the Caribbean coast. The majority of Ngäbes live within the Comarca Ngäbe-Buglé, a semi-autonomous province created in 1997, which has a population of over 200,000 (INEC, 2019), and has the highest rates of poverty among the country's major political districts (MEF, 2018).

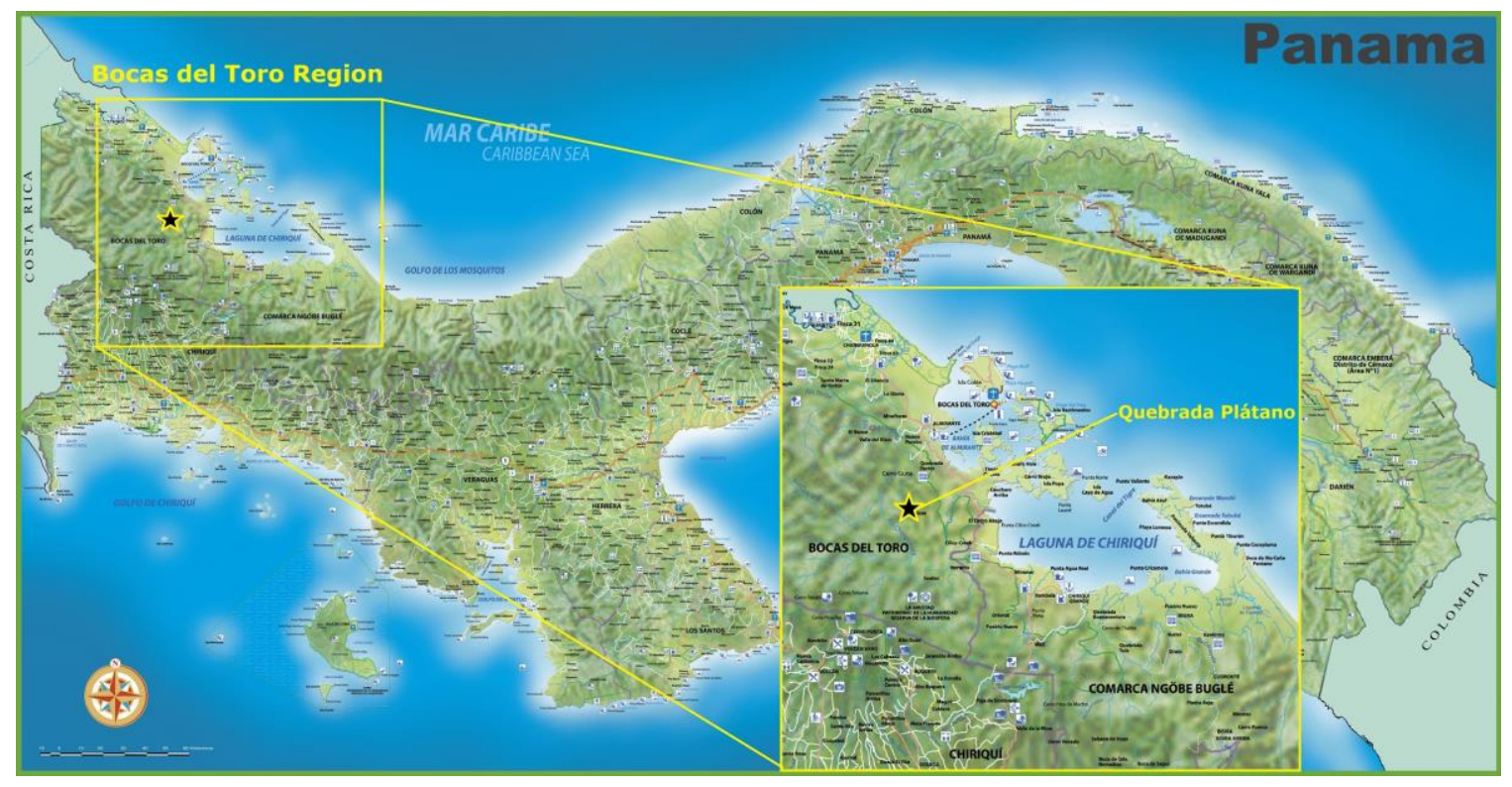

Figure 3.1.1. Map of Panama indicating the location of the Bocas del Toro Region and the specific location of the small, rural community of Bocas del Toro called Quebrada Plátano where the author spent two years from 2017-2019. Adapted from OnTheWorldMap, n.d.

I spent two years working almost exclusively in a small community of roughly 250 Ngäbe subsistence farmers called Quebrada Plátano, located in the Province of Bocas del Toro near the Caribbean coast of western Panama (see Fig. 3.1.1). Bocas del Toro is a small, rural province relatively cut off from the main economic centers of the Pacific coast. Once dominated by the banana empire of the United Fruit Company, it is now home to many small communities of Ngäbe subsistence farmers that make up a majority of its population (INEC, 2010). Beginning in the mid-20th century, due to overcrowding, many Ngäbes began to migrate from the region 
known as Ñö Kribu, especially along the Cricamola River, towards the west, settling on lands abandoned by United Fruit or other foreign enterprises, or seeking jobs on the banana plantations surrounding the border with Costa Rica. As families grew, small communities formed and organized in order to obtain government services like schools, basic health services, and access roads.

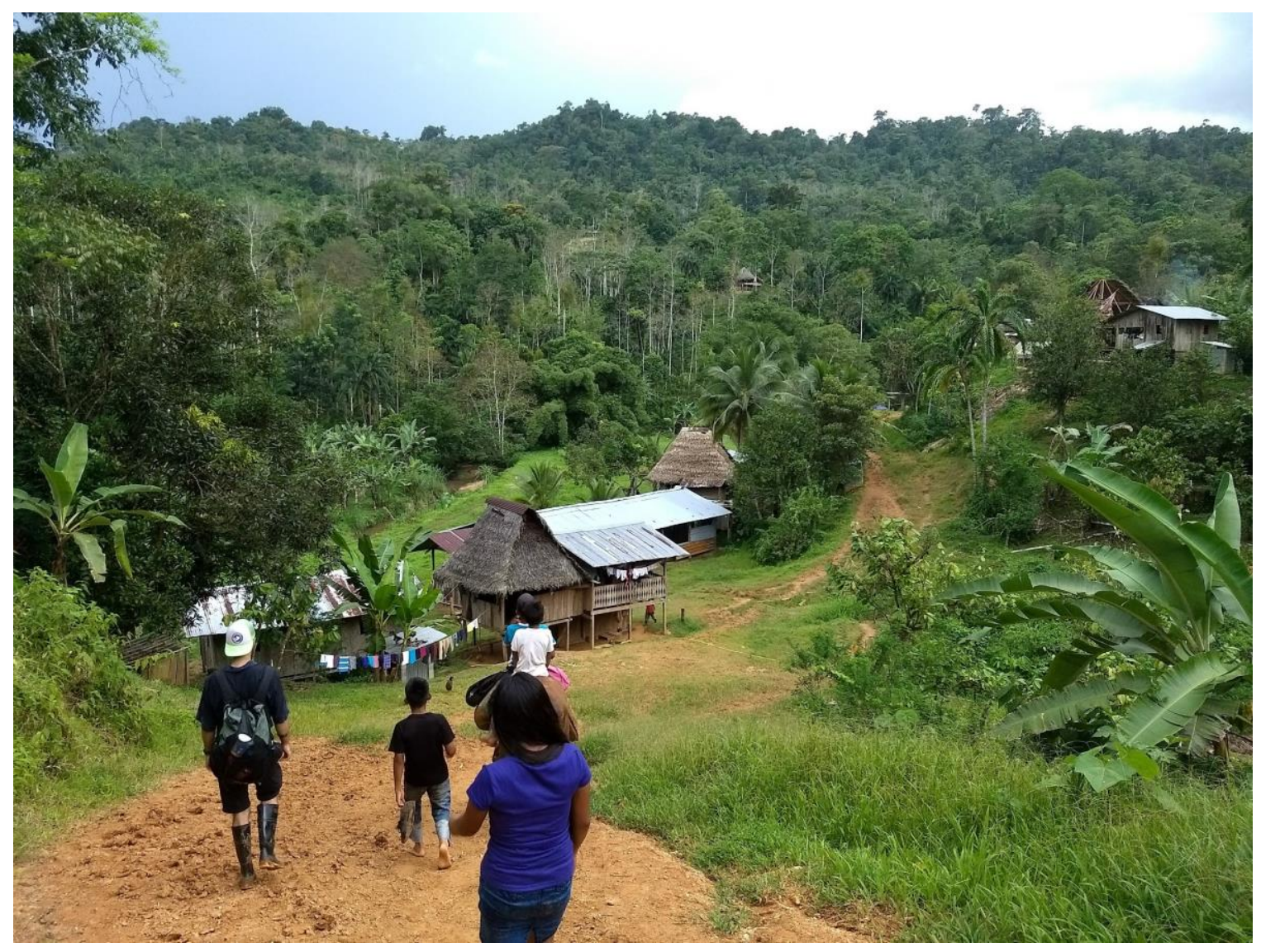

Figure 3.1.2. The author descends the steep, muddy footpath at the entrance to the central section of Quebrada Plátano, with children in tow. The creek and part of the school's soccer field is visible center-left. The long, steel-roofed structure in the center is the communal meeting house. Typical houses with a palm thatch section for the kitchen and steel-roofed section for sleeping quarters, are typically occupied by 8-15 people. (Graham Schneider, 2018).

Quebrada Plátano was first settled in 1968-1969 by two men and their families, slowly growing into a small established community with an elementary school by the 1990s. A grueling hour-long hike is required to reach the community from the 
last passable road, where regular public transportation comes from the nearest developed town of Almirante, an hour drive away. The community encompasses a small, lush tropical valley where people live along the steep, treacherous, forested slopes on either side of a small creek. It is over an hour walk along the creek from one end of the community to the other, and there are several other small communities up to an additional 1 - 4 hour hike farther upland. Houses are built on elevated platforms from local timbers with a mixture of palm thatch and corrugated steel roofs (see Fig. 3.1.2). The community has no electricity other than several people who own small solar panels, and unsafe water is typically carried in buckets or piped directly to individual homes from creeks. A majority of households open defecate directly into creeks, while others own and use pit latrines. Weak cellular signal can be found by climbing up the steep hillsides on either side of the valley. Traditional staple foods of bananas, various root vegetables, fruits, and local fauna are cooked primarily over wood fires. However, the purchase of rice, sugar, flour, canned fish, frozen chicken and use of propane cook stoves is now commonplace. The most important economic activities are cultivation of cacao, raising of livestock like cattle and pigs, selling timber, construction jobs within the community (e.g. house construction and lumber milling). Several families have opened small stores in their homes where they sell basic food and household items they carry in from town, and typically give people, especially trusted family members, an open line of credit since people rarely have cash on hand. The lack of road access is a significant economic barrier -- many types of agricultural products are not as profitable as they are elsewhere due to the high cost and labor involved in transporting them into town. All families rely heavily on government welfare assistance for a majority of their income, which includes the Red de Oportunidades conditional welfare program that pays $\$ 50 /$ month to qualifying female heads of household, Beca Universal that pays $\$ 90, \$ 120$, or $\$ 150$ per trimester to parents in order to buy school supplies for each to primary, middle, or secondary school student, respectively, who passes their classes, and a program that pays $\$ 120 /$ month to anyone over the age of 65 . 
Population is growing quickly, as women often have 8 or more children, and it is common to see four generations living in one household. With each generation, sufficient land for subsistence farming is becoming more scarce, and a majority of young people are now leaving to seek jobs in the city. Many families have members working in the capital who send money home.

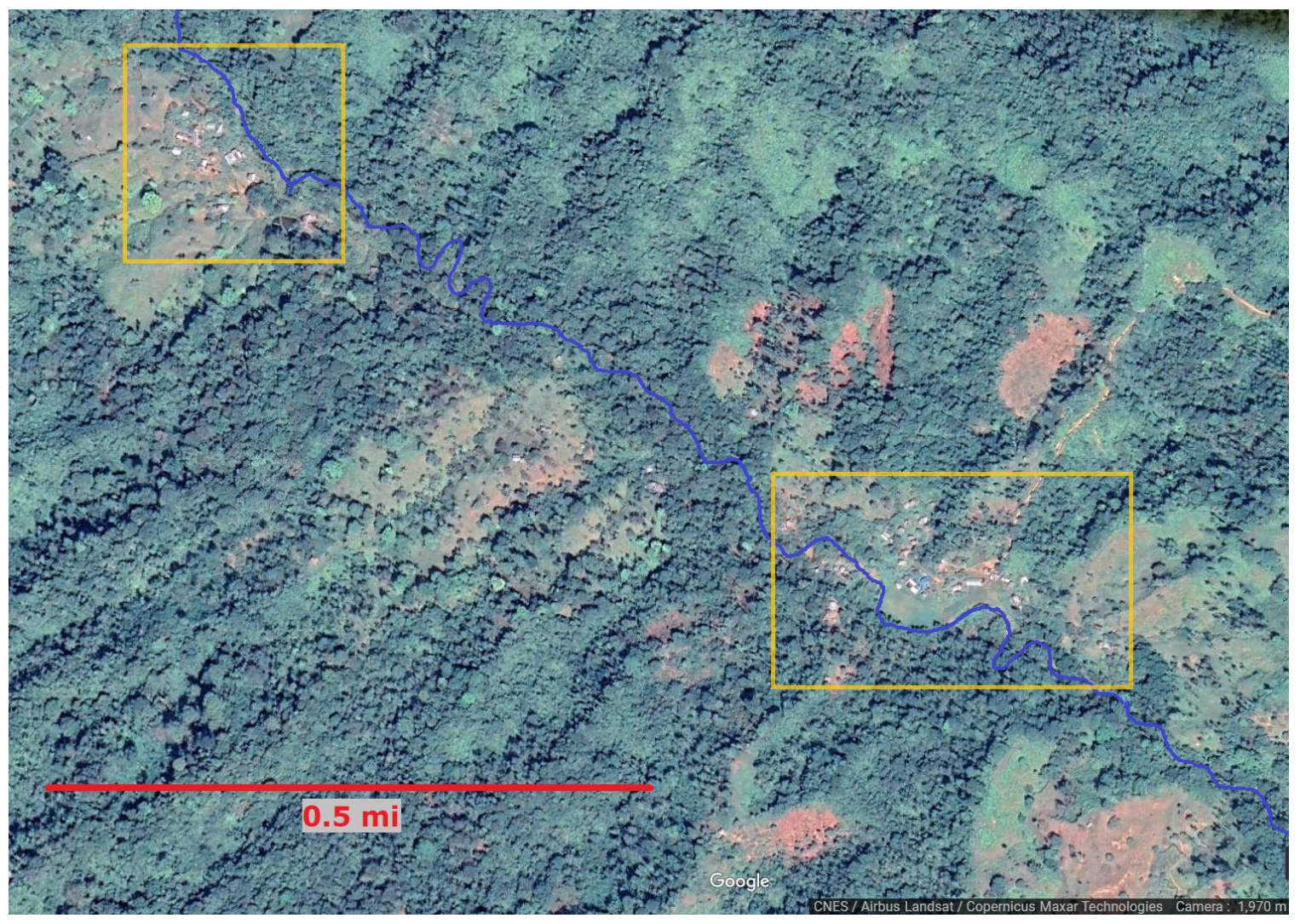

Figure 3.1.3. An aerial photograph of Quebrada Plátano dated 2018, showing the two primary sections of the community, each originally settled by two men and their families in 1968. The primary school, church, and community meeting house are located in the bottom-right section, where the access footpath is also visible. The creek that runs through the valley is the lifeblood of the community. Cleared land is either cow pasture (top-left, bottom-right, center), or cleared for planting. Adapted from Google Earth.

Although Quebrada Plátano is located just outside the semi-autonomous Comarca Ngäbe-Buglé, cultural identity is highly valued and Ngäbere is spoken as often as Spanish, although this is shifting as young people begin to insist on speaking 
Spanish exclusively, which they learn to read and write in school. People are inherently distrustful of outsiders, government officials, and anyone who is not Ngäbe, and generally view money as a mysterious, ephemeral concept, being metered out slowly by wealthy outsiders who oppress them and view them as inferior, although this view is changing as the youngest generation begins to interact more with the mainstream economy. Traditional gender roles are strict, and are only just beginning to change in this community as they already have in those nearby with more access to the outside world. Many older people fear these rapid cultural shifts, which are especially strongly opposed by members of an evangelical religion introduced by missionaries in recent decades, whose members make up about half the population. They often blame changing gender and social norms for social problems like alcoholism, drug use, domestic violence, and crime they view as rampant in other communities. However, the vast majority of adults and children greatly value education and especially view graduation from secondary school as a ticket out of poverty, for both men and women. Most parents now strictly forbid girls from marriage or having children until after they have exhausted all possible opportunities to attend secondary school, and underage pregnancy is now rare, which is remarkable considering that arranged marriages of prepubescent girls to older men is a part of traditional Ngäbe culture still practiced in some regions of Panama. Both men and women need to seek out partners from other communities because almost everyone in Quebrada Plátano is related, and where they settle down depends on which partner has or will inherit land. There is a strong desire for young people to leave their parents' house and build their own, usually nearby, to raise their family. Extended families tend to remain cohesive with parents sharing child rearing responsibilities with cousins, aunts, uncles, grandparents and greatgrandparents.

Community organization is structured around the primary school, which has three full-time government teachers from outside. The parents association works closely 
with the teachers to maintain proper function of the school, and many parents actively participate in workdays and meetings. The evangelical church is also highly organized with nearly half the community participating regularly. The community is also required to have a health committee to promote community health projects, and a water committee to maintain a government-built aqueduct; however, both these groups were either nonexistent or dysfunctional when I first arrived, leaving the community's recently constructed aqueduct damaged almost beyond repair. The absence of road access significantly restricts the ability of the already overstretched local government agencies to work in the area, shifting much of the burden of developing and maintaining communal infrastructure like improved water and sanitation services, and educational facilities to the residents. However, a lack of cohesion and deeply rooted family tribalism often impede their ability to take on these projects, and make fostering community solidarity and the organizational and technical training of local leaders critical aspects of any development strategy.

Residents face significant health problems due to poverty and lack of infrastructure, with infants and young children frequently suffering water and insect borne diseases like giardia and dengue that cause fever, diarrhea, and malnutrition, and disabling or disfiguring skin infections. General knowledge about the transmission and prevention of disease is also lacking, with open defecation common and handwashing rarely practiced. Birth control and contraception are not widely available and often forbidden on religious grounds, and knowledge about family planning is low. The community is under threat from a growing HIV epidemic affecting mostly young, Ngäbe people in the nearby Comarca Ngäbe-Buglé. Until political changes in 2019, a basic medical team would visit the community every two months to administer vaccines to children, examine pregnant women, and give out basic medicines. Without this critical service, the community is left vulnerable with almost no available health services, other than transporting patients to the hospital in an emergency -- which often involves carrying them on an hour-long grueling 
hike, followed by 1-2 hours additional motorized transport before reaching the nearest staffed medical facility. Because of the costs and difficulty associated with medical transport, most families rely on various traditional herbal or spiritual remedies, and only seek medical help if the patient's life is in imminent danger or a disease is particularly advanced, and once they manage to secure sufficient funds. Families must often make the difficult choice between bringing a sick or injured loved one to the doctor and feeding their children, although the community is usually willing to chip in to help those particularly in need.

\subsection{The Tool that Makes Life Possible}

The machete (Fig. 3.2.1) is probably the most important and versatile tool of the rural subsistence farmer, especially throughout the tropics, due to its affordability and usefulness. In Quebrada Plátano, most households contain more machetes than people, and they are used for anything from cutting grass around homes and

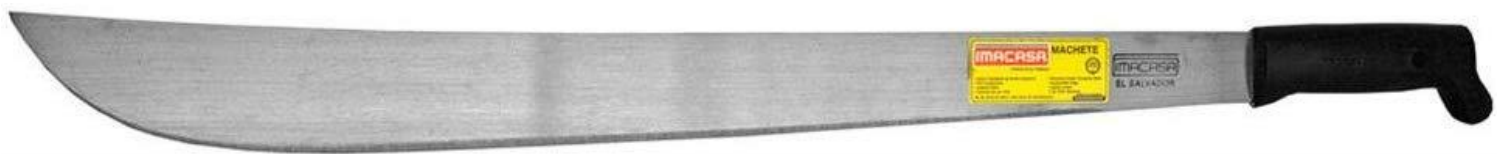

Figure 3.2.1. The typical machete used by people in the area, with a lightweight 26 29 inch ( $0.66-0.74 \mathrm{~m}$ ) long carbon steel blade that flexes easily, and a molded plastic handle. I observed several similar brands at local stores, but most people seemed to prefer this specific model.

buildings, to clearing brush in cow pastures, clearing the dense jungle to plant cacao, bananas or other crops, pruning and harvesting cacao or other fruits, cutting down small trees and bamboo, peeling fruits and vegetables, opening coconuts, general construction and carpentry, digging, splitting firewood, hunting, self-defense (against animals and snakes), or even as a walking stick on rough terrain. The machete is used by men, women, and children, with women using them especially for domestic tasks like peeling fruits and vegetables, and splitting firewood. Men 
tend to use them for labor intensive tasks like clearing large plots of land. However, women frequently help out with all types of farming tasks when necessary. Children first pick up a machete before they can walk, and are expected to use them soon after they can (see Figs. 3.2.2 and 3.2.3).

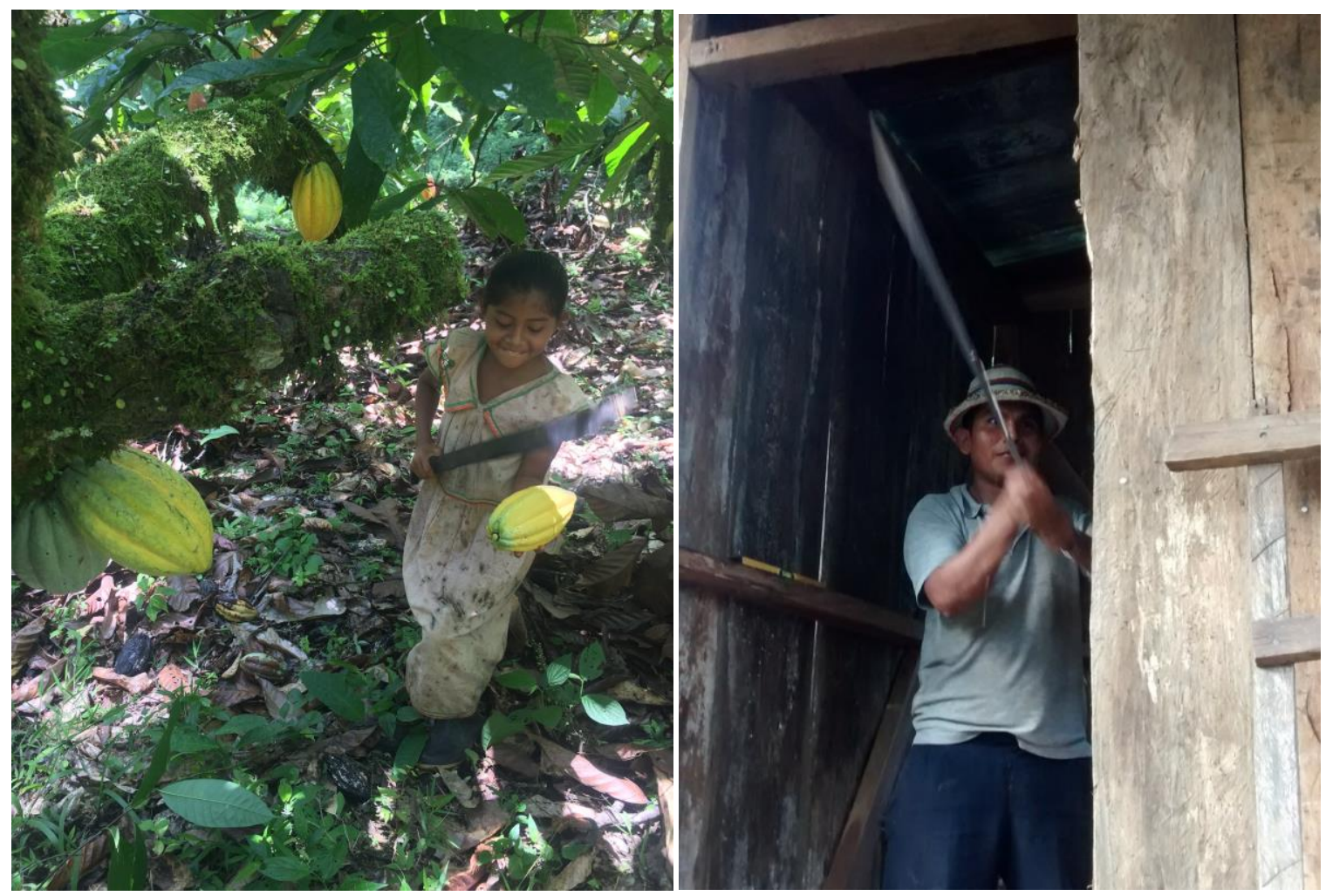

Figure 3.2.2. Left: A young girl uses her machete to open a cacao pod and remove the seeds used to make chocolate. Cacao production is one of the primary economic activities in the area, and the entire family is expected to help, especially at harvest time (Irene Burgoa, n.d.). Right: A man uses a machete to trim down a door frame that was slightly too large while building a new house. The machete is a versatile tool used in all types of jobs (Author, 2018).

Most people do not stray far from home without their machete. They can be purchased in town typically for $\$ 4-5$, and if properly cared for can last a decade or more. They need to be regularly sharpened with a cheap triangular file, or occasionally with sharpening stones, before and during use. It is obvious when the edge becomes dull while working, as noticeably more effort is required for cutting. Men especially take great pride in the sharpness of their machete, often as if it is a 
reflection of their manhood. Machetes used for hunting are often sharpened with a very small angle for maximum sharpness, while those for general work purposes are sharpened to a wider angle for more durability. People purchase almost exclusively the style of machete in Fig. 3.2.1., with a 26 - 29 inch (0.66 - $0.74 \mathrm{~m}$ ) long blade, and many prefer the brand Imacasa (El Salvador) over all others because they claim the blade holds its edge longer, is less prone to bending, and is more durable overall. Over time as the machete continues to be sharpened, the blade becomes narrower and develops a sharp, pointy tip. The machete can be sharpened for years until the blade essentially disappears.
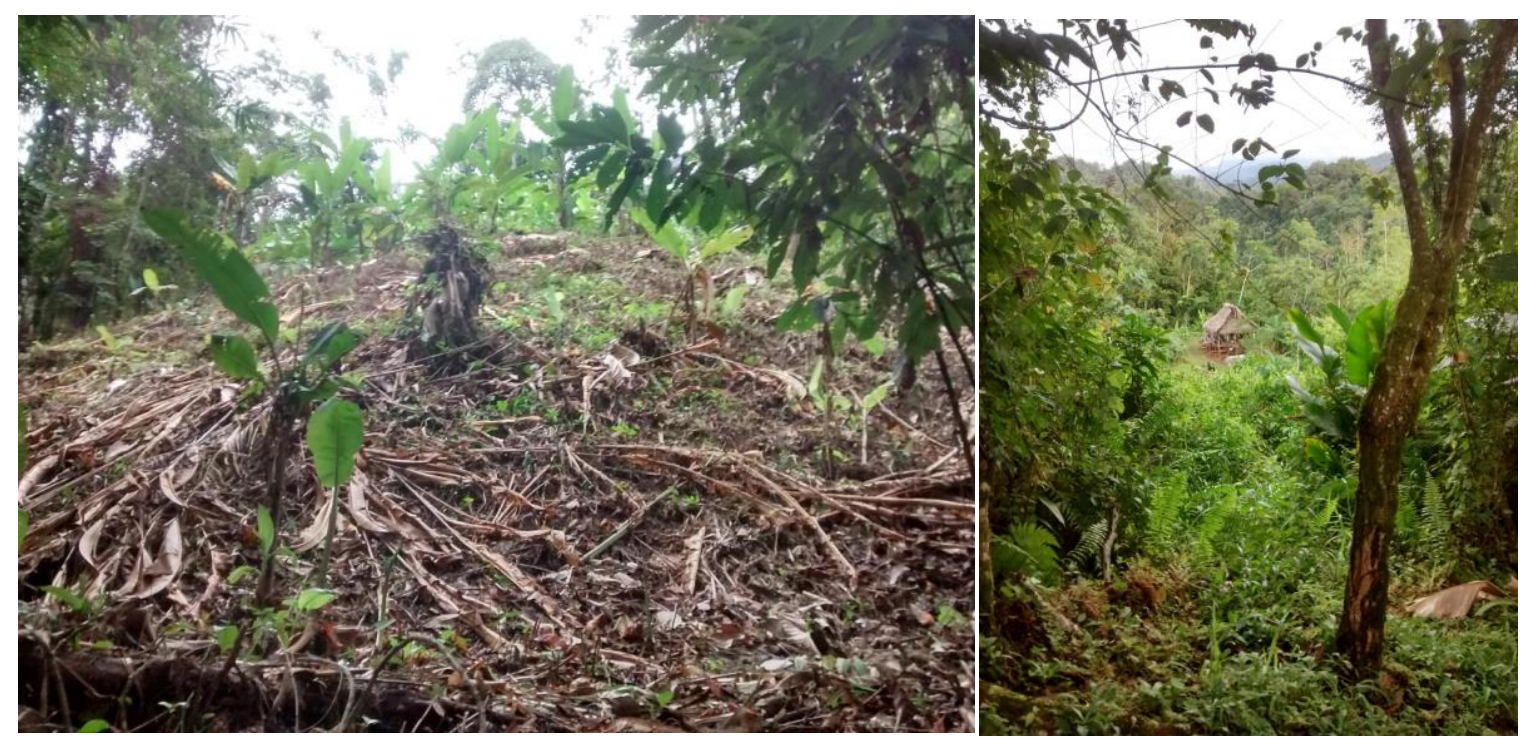

Figure 3.2.3. Left: A freshly cleared hillside ready for planting. This landowner hired several helpers who spent about 10 full workdays cutting down everything by hand with machetes, in order to plant bananas and other staple crops. Right: A typical homestead, cut out of the dense jungle with the help of machetes. The work to keep the jungle, and the dangers it brings, from encroaching is unremitting (Author, 2019).

Through conversations with Ngäbe people in Quebrada Plátano and throughout the Bocas del Toro region, it is apparent that the machete is an important part of their cultural identity - that it symbolizes their desire and ability to live off the land. Many mestizo, Latino, and Afro-Panamanian farmers in the region rely heavily on broad spectrum herbicides to clear land for pastures and planting, while Ngäbe people 
generally take great pride in their organic growing techniques and ability to work hard using hand tools.

\subsection{Machete Accidents and Injuries: A Dangerous Fact of Life}

The physical lifestyle of a farmer has its risks, and people in the community regularly showed me recent injuries or recounted past ones. They often explained that this is part of the lifestyle and that shying away from risks would mean their families would go hungry. Over the course of my two years there, I began to realize how frequent and serious injuries due to machete accidents seemed to be, relative to other types of incidents I saw or heard about. One day while working in my garden, a neighbor came running down the hill yelling that her cousin had cut himself. She was trying to round up men to carry him out to the road but most of them were off at a church service in another community. After a year and a half, I had become accustomed to this type of scenario and decided to see what had happened. A five minute hike up from their house a young man lay on the ground, apparently unconscious, a bloodsoaked rag tied around his foot. His cut open rubber work boot lay nearby. He had been cutting down brush alone and nobody knew when the accident occurred, but he had managed to tie off the wound himself to stop the bleeding before losing consciousness. Since men were in short supply, I agreed to help carry him. We moved him onto a blanket and tied each end to a long board and hoisted it up on our shoulders, one man in front and one in back. The four of us then began the grueling, hour-long hike, switching off when one person got tired. It had been raining heavily and the path was treacherous and slippery, with spots where the sticky mud was knee-deep if you stumbled off one of the slippery logs buried underneath the surface (see Fig. 3.3.1). Twice my legs almost slid out from under me on the steep muddy descent as my shoulder burned and my mind screamed for me to call for a replacement, the young man swinging, still unconscious and unaware, wrapped in his blanket. During the ordeal I realized that for the men I was with, this 
was a normal occurrence, simply a part of life. I began to wonder whether it really had to be this way. What could be done to make transportation to the hospital easier? What could be done to prevent these injuries in the first place? What could this young man have done to avoid this situation entirely? The engineer in me saw an opportunity -- if workers across the world using all different types of tools and machines have access to effective personal protective equipment (PPE), why should these people be any different? In the end, the young man reached the hospital and quickly recovered, left with a hospital bill he could not pay and a follow-up appointment he could not afford. I went home with a painful pressure sore on my shoulder and an aching back that kept me from leaving the house for a few days. However, not every accident story ended this way. Machete injuries often left lasting, debilitating effects, robbed people of their ability to work, their livelihoods, and caused children to miss school. 


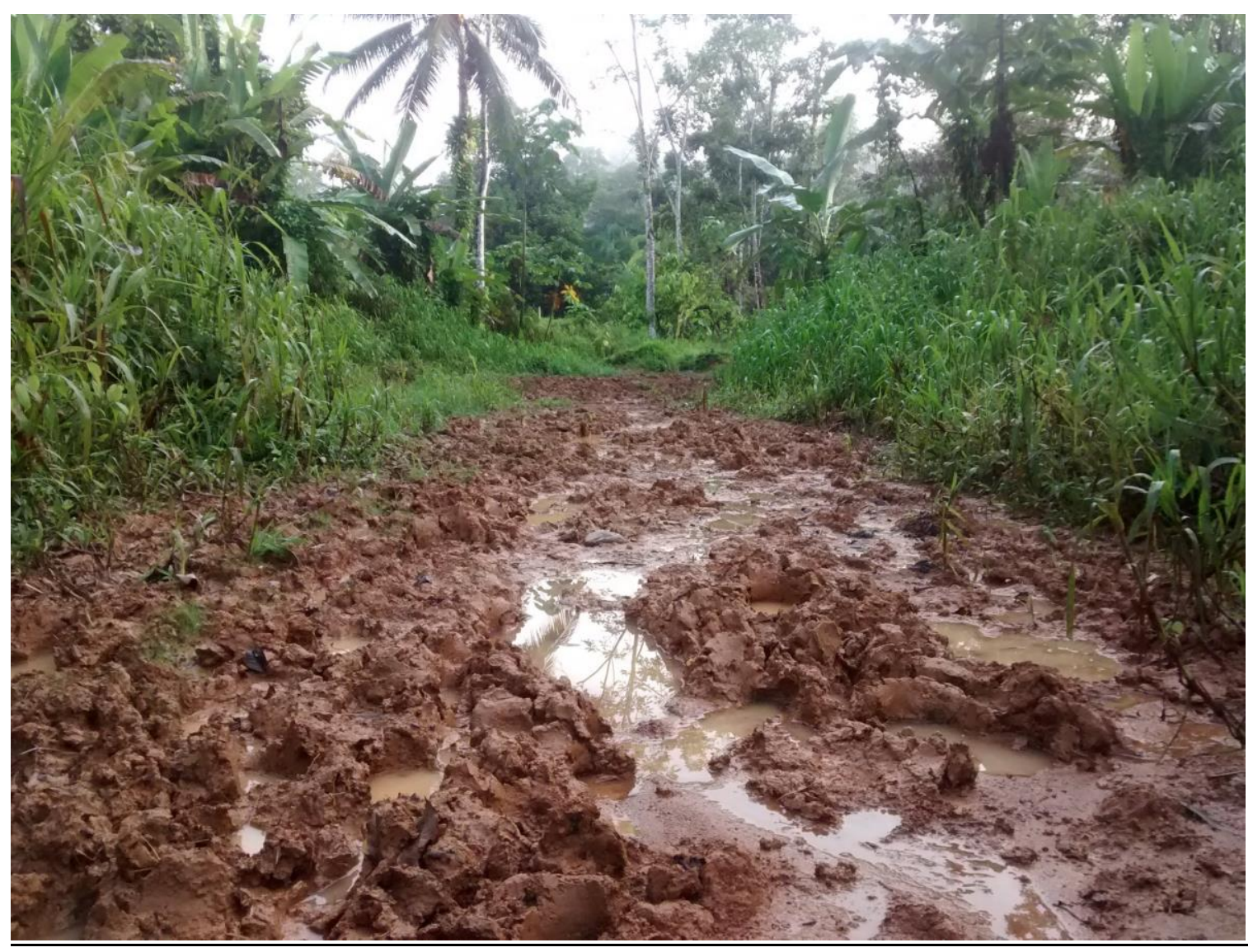

Figure 3.3.1. The footpath leading to and from Quebrada Plátano has several extraordinarily muddy stretches like this one that are exacerbated by heavy rains during much of the year, making transportation of medical patients, and access in general, extremely difficult. (Author, 2018).

\subsection{Machete Injuries: A Problem Worth Solving}

To understand whether this is a problem worth solving, it is useful to consider the wider context and potentially broader impacts beyond one small village. Since machetes are used throughout the world by poor, rural farmers, it is safe to assume injuries are commonplace outside of this one small community. Over the course of two years I worked with people in 20 other rural Ngäbe communities in the Bocas del Toro region. Anecdotal evidence suggests that machete accidents are common throughout this region amongst Ngäbe farmers, and more work should be done to measure the problem in other geographical areas. Yet, I did not identify one 
commercially available product designed specifically to prevent accidental injury while using a machete. Although many poverty reduction projects focus on large scale, infrastructural improvements that address people's most basic needs, smallscale technologies that help people in small ways are needed and often have fewer barriers to implementation, while individually owned products are often easier to implement than communal ones (Mattson \& Wood, 2014). Projects geared towards the rural poor are also essential now, as increasing urbanization leaves less educated people or those less able to adapt to city life behind and the gap increases between the urban and rural poor (Mattson \& Wood, 2014). It should also be top priority to work with those people at the very bottom of the economic ladder (Polak, 2008). To evaluate whether any project to reduce the conditions of poverty should be pursued, it is critical to consider the impact on basic needs like health, nutrition, education, and housing (Jaiswal, 2008). The problem of machete accidents ties directly to these basic needs for subsistence farmers dependent on physical labor to obtain food and housing, and to send their children to school. An injured family member puts a tremendous burden on the rest of the family; for example, an injured parent may cause children to skip school in order to work, or force young girls to stay home and care for younger siblings while their mother is taking the place of her husband on the farm. It puts difficult economic burdens on families no matter who is injured or becomes permanently disabled. Therefore, preventing these scenarios is certainly worthwhile in the greater context of reducing poverty.

\subsection{Household Interviews in Quebrada Plátano}

\subsubsection{Purpose of Household Interviews}

I came to Quebrada Plátano as a Peace Corps volunteer with a set timeframe of two years and a job description to work on building capacity for community water and sanitation infrastructure and basic health education. Therefore, I did not arrive with 
the assumption that I would discover a problem that could be solved through a participatory product design process. However, throughout my time there, while carefully studying the community and culture, and building relationships, it became clear that the problem of machete accidents was a worthy choice to pursue the creation of a new product. To capture the full context of the problem, and begin to imagine the possibilities for co-creation, co-design, co-development, and co-venture of a solution with those who will ultimately benefit, required that I invest a significant amount of time living and working with local people, struggle in the same ways they struggle, learn their language, develop a deep understanding of their culture, values, and their inter- and intrapersonal conflicts, and develop deep, lasting personal relationships with men, women, and children alike. After I identified the problem of machete accidents, it became clear that a more systematic method for collecting contextual information specifically related to the problem was necessary. Given the relationships and trust I had built in the community, I conducted a series of open-ended household interviews based on a loose set of questions in order to gain a more detailed understanding of the problem, its cause, impact, severity, frequency, the various requirements that would aid in future product design, and ultimately, the people's level of desire for a solution.

Household interviews would not be meant purely for information extraction, but rather would be a participatory process that emphasized exchange of ideas and open dialog. This was a key preliminary step in the co-design process aimed at identifying enthusiastic co-designers and counterparts, and even potential local manufacturers and future business partners. Each interview conducted would be considered as an individual case study, and taken together, these cases would help illuminate the significance of the problem, the specifics of its impacts, and the level of enthusiasm and interest throughout the community in finding a solution. 


\subsubsection{Interviewing Methods}

Shortly after the ordeal of carrying the young machete injury patient out to the road, I began the interview process with an informal conversation with a local man who came to my home complaining about multiple recent machete injuries and requesting some basic first aid supplies. This conversation was my first indication that there may be a high level of enthusiasm for a type of PPE that protects against machete injuries (MPPE). In fact, he claimed to have been thinking about the possibilities for years but was never able to come up with a good solution on his own. In addition to his recent injuries, he showed me at least 15 older scars, on his feet, shins, around his knees, on his hands, forearms, even the back of his shoulder. Many of these injuries occurred while working in relatively extreme conditions, clearing dense jungle with lots of overhead vines and material that can fall down unexpectedly. Other injuries were due to fatigue and loss of focus after working all day, or slipping and falling in wet, muddy conditions. He emphasized to me the dangers and tremendous level of risk people face on a daily basis because of their highly physical lifestyle, and mentioned snake bites, insect stings, and thorns as being additional safety concerns. In the end, he pleaded with me for help coming up with a functioning solution to protect himself and his family members from injuries, and suggested a price of $\$ 20$ that he would pay for it, which is a significant investment for him.

Based on this conversation, I developed a list of questions as a guide for future interviews that aimed to gauge the level of concern over the problem of machete injuries, their relative frequency and severity, to understand the different scenarios that lead to accidents, the locations on the body where injuries occur, which groups of people are most at risk, long term quality-of-life and financial impacts, and level of enthusiasm for using an MPPE solution; and to collect ideas on what MPPE products would look like and what the requirements would be. Due to my 
understanding of the culture, I also decided it was important to show people a concrete demonstration of a possible solution right away, in order to avoid a purely abstract conversation which would be less fruitful. Before starting the interviews, I obtained a sample of a tightly woven $0.24 \mathrm{~kg} / \mathrm{m}^{2}$ DuPont Kevlar fabric from the United States that I suspected could resist cutting with a strong blow from a sharp machete, even though it is quite light and pliable.

There are roughly 30 distinct households in Quebrada Plátano, and I originally set out to conduct interviews at each one. However, time constraints, bad weather, illnesses, and several families being out visiting relatives or working elsewhere left me with 16 interviews in total, conducted over the course of three weeks in AugustSeptember 2019. Since it is nearly impossible to schedule visits in advance, and without the benefit of telephones, it was necessary to walk from house to house, usually arriving unannounced, and frequently finding that the majority of the household was out working on the farm, or had traveled into town that day. Many interviews were conducted in circumstances that would seem quite chaotic to outsiders: while families were tending to household responsibilities, hosting other guests, or preparing to head out to the farm. There was a marked under representation of teenage boys and young men, who prefer to minimize time spent at home, and were often out working, playing sports or games, or had left to find seasonal farm work in other regions or permanent jobs in the capital. As is to be expected in this culture, it was difficult to encourage women and children to open up and participate directly in the conversation, especially if older men were present. However, women occasionally directed their questions to their male partner or other men present, who would then address me directly, a cultural norm I had become accustomed to.

The two main hypotheses inherent during each household interview case were: (1) that machete accidents are a ubiquitous and serious problem in the community and 
that people see it that way, and (2) that there is widespread enthusiasm and interest in coming up with and eventually using an effective solution to prevent these injuries. According to Lipson (2005), when developing and analyzing case studies, it is not possible to come to conclusions without carefully understanding the context of each case. Chosen cases should be categorized as "easy", "typical", or "hard". An "easy" case is one that is already assumed to validate the hypothesis due to previous knowledge about the subjects, and serves as a minimum threshold for the hypothesis that can help illustrate the mechanism of the argument in practice. A "hard" case is one assumed likely to refute the hypothesis, and sets a high threshold for the argument. If it applies in this case, the argument is strong and convincing, if not, it can help define the limits of the hypothesis. "Typical" cases are average ones that show no evidence of previous bias towards the hypothesis, and are useful for detailed explorations of relationships among variables and proposed causal mechanisms (Lipson, 2005). Since I had previously developed close relationships with each of the 16 interviewed households, I had a good idea of what category they fit into beforehand. Several cases can be considered "easy", where household members had already expressed to me their concerns or enthusiasm related to this topic, or had worked with me on previous projects with great enthusiasm and curiosity. Several are "hard" cases -- people who had previously demonstrated little interest in new projects, a pessimistic attitude, or a penchant for preserving the status quo. The rest can be considered "typical" cases.

After completing the 16 interviews, I divided the information gathered into 9 different broad categories of responses in order to pick up on common themes. These categories are: (1) the perceived severity of the problem and who is most affected, (2) machete accident scenarios and injury details, (3) other types of accidents and injuries, (4) impacts of machete injuries to health and quality-of-life, (5) economic impacts of machete injuries, (6) level of enthusiasm about using an MPPE product, (7) affordability requirements and business model ideas, (8) specific 
product design suggestions and requirements, and (9) unrelated interest in the raw material for other purposes.

\subsubsection{Interview Results: Realities and Perceptions of the Problem}

Due to the limitations of the interviews -- lack of a representative sample size, and a wide variety of interview quality and levels participation due to sociocultural factors described previously -- I will refrain from presenting results in a quantitative way. However, several very useful themes and ideas emerged from the interview process. First is that this problem seems to directly affect men almost exclusively. Though several women did report past machete injuries, they seemed to be less common, and more like "freak" occurrences than a part of life. One man explained to me that this is because women work more slowly and carefully than men, and that women don't participate in some of the more dangerous tasks. Since women participated minimally in the conversations, it was difficult to gauge how this problem directly affects them, but through my previous personal experiences observing the aftermath of machete injuries, I know that an injured husband, father, son, or grandson places a high burden on women and girls, who must take up additional labor and responsibilities while that member of the family recovers, or if they become permanently disabled.

Another surprising result was that the problem was not as universal, even amongst men, as I first hypothesized, as several "typical" case households reported no history of machete accidents. However, when pushed further, some eventually admitted to an injury they thought was too insignificant to mention either because they recovered quickly, it did not cause lasting disabilities, or occurred too long ago. Half of those who had never been injured admitted that they often hope or pray that this never happens to them or their family members, and that they still view it as an issue of great concern. 
A clear majority of interviewed households had at least one member of the family who had been injured in a machete accident, almost entirely men, ranging from 9 to 75 years old. A similar majority also expressed that they are concerned about this problem and that it is widespread. Half of cases demonstrated a clear enthusiasm for using some form of MPPE to prevent these injuries, including all the "easy" cases and several of the "typical" cases, while multiple "hard" cases with a history of injury expressed that this is an inevitable aspect of life and that nothing could be done to prevent it. Only a small number reported ever receiving professional medical treatment following an injury; however, several people reported lasting disabilities due to injuries, especially on the hands, that make work painful and difficult, and are likely due to a lack of necessary medical intervention. The direct economic impact and costs associated with going to the hospital are a major barrier for seeking treatment when necessary.

Injuries were most common just above, on, or just below the knee, followed by the hands, then lower leg and foot, then head/face/torso, with arms and shoulders the least common injury locations reported. Knee injuries generally occur when chopping down medium sized brush or small trees in a moment of fatigue, if the machete ricochets of a hard object unexpectedly, or cuts through something much softer than expected. When cutting down taller plants, people tend to work in a more upright position swinging the machete almost vertically with the tip pointing towards the ground. This can lead to foot and knee injuries. When cutting short grass, for example around the house, people tend to bend over, sometimes with one hand on the knee, and swing the tool in a wide sweeping stroke almost parallel with the ground, which seems to be safer but does sometimes lead to shin and hand injuries. Hand injuries are usually due to slipping and falling while carrying the machete, due to the treacherous, steep, often extremely muddy and slippery working conditions. On a daily basis people harvest and carry heavy loads of foods like bananas up to an hour in traditional homemade sacks called kras that place the 
weight on the head or shoulders and back, sometimes using their machete as a walking stick to maintain balance on rough terrain, or else holding it dangling in front of them or positioned strategically along their forearm to try and avoid injury if they slip and fall. Injuries to the head, torso, and arms are considered "freak" accidents that happen especially while clearing dense jungle that requires cutting down thick mats of vines above the head, which can cause heavy material to break loose, falling down and causing the machete to strike the worker from above.

Showing the Kevlar material to people during interviews proved invaluable as it usually expanded the conversation and increased enthusiasm overall. It also demonstrated a cultural pattern that people refuse to accept any claim about a product at its word, requiring a full demonstration before they will believe it. Almost all the interviewed households requested me to demonstrate whether the fabric was as resistant to cutting as I claimed, which is an important fact for the future development and implementation of product-based solutions. More discussion of the significance for product marketing can be found in Section 5.3.

Several people expressed interest in using the Kevlar material in ways not related to MPPE. Some men wanted to use it to make a durable, professional looking bag or sack for carrying items, while several women were interested in unraveling the individual fibers of the fabric in order to make an extremely durable version their traditional kras. This is important information for evaluating different product implementation and manufacturing options, as well as business model options, since unintended use or misuse of products could ultimately lead to failure of the project's goals if not predicted and accounted for in advance (see Section 5.1). 


\section{Chapter 4. Machete PPE Product Designs Come into Focus}

Although the importance of extensive effort dedicated to understanding the context of the problem, and developing relationships with local beneficiaries in order to codesign products and cooperate in sustainable business enterprises cannot be understated, the careful design of the physical product itself remains enormously important to the success of any enterprise in a resource-poor BoP market. After all, the product must actually solve the problem it is designed to solve, and people must be willing and able to use it. It is important to consider that products developed for wealthy markets cannot always be considered suitable for the poor, or easily adapted to be so (Castillo et al., 2012). For example, product designs need to take into consideration hostile conditions or lacking infrastructure, limited manufacturing capacity, locally available resources, ease of use, portability, and often human powered solutions (Castillo et al., 2012). In fact, many of the principles of the AT philosophy should not be ignored when it comes to product design -- as long as they stem from the context and requirements gathered during the participatory design and creation process. Echoing the AT philosophy, Castillo et al. (2012, p. 6) mention that "solutions need to be simple, functional, potentially open-source artefacts and systems with an inherent capacity to transform human lives by enabling users to become empowered and self-supporting entrepreneurs".

\subsection{Analysis of Key Product Attributes}

In an analysis of 64 different products developed for BoP markets across a range of different sectors, Whitehead (2015) surveyed designers and users in order to develop a set of attributes that make products effective and successful in their given marketplace. The primary 8 attributes identified that generally determine the success of products are: (1) functionality, (2) usability, (3) durability, (4) repairability, 
(5) sustainability, (6) affinity, (7), desirability, and (8) affordability. All of these attributes in some way relate directly to the physical design of the product, although several are closely related to the business model, supply chain considerations, and marketing strategies. All eight of these principal attributes should be carefully considered throughout the entire co-design process, where they can be used as a guide that keeps the design team on track. Additional important considerations identified by Whitehead (2015) in surveys of product designers are: funding sources, user involvement, user needs, product distribution, scalability, manufacturing location, overall quality, and convenience of adoption. Several of these considerations will be considered in more depth in Chapter 5. Similar to the analysis of an agricultural technology in rural Peru in Hayes (2017), I will use these 8 critical product attributes as a framework to develop product requirements for MPPE which will coalesce into a more focused picture of specific product solutions.

\subsubsection{Functionality}

Put simply, functionality is a measure of how well the product serves the purpose for which it is designed. In the case of MPPE, high functionality would mean that the product(s) reduce(s) the frequency and severity of machete-related injuries, in order to effectively alleviate the negative health and financial impacts on Ngäbe farmers in Bocas del Toro caused by these accidents.

Based on information gathered during household interviews, machete injuries most frequently occur on the leg, especially just above and below the knees, but also on the shins and feet. Therefore, a functional PPE product needs to cover the entire leg, from the tips of the toes up to at least $0.1 \mathrm{~m}$ above the knee, though it does not necessarily need not cover the posterior side of the leg, as injuries there are extremely rare. Depending on the material used, this product could take the form of a tall sock that includes a way to secure it from falling down below the knee, or as 
suggested by one local man, a protector that straps onto the leg either underneath or over the pants, with a small pocket into which the toes are inserted.

Injuries are also quite common to the hands, which tend to cause more severe, debilitating injuries that have lasting impacts on quality-of-life. A glove-like MPPE product that offers protection to the palm of the hand and fingers would be necessary to avoid some of the worst injuries. Current commercially available protective work gloves may already be functional as MPPE. Another option, suggested during interviews, would be an affordable machete carrying case product that allows users to carry the machete without risk of injury while slipping and falling, though this would not prevent all types of observed hand injuries. Products like this are locally available, and I observed several home-made versions using flattened PVC pipe. However, they are often prohibitively expensive, and many people prefer to carry the machete in-hand in case it needs to be used quickly.

The material used in any machete PPE product above all must demonstrate that it can withstand the types of forces typically inflicted on the body in different realworld accident scenarios, and prevent or significantly reduce the severity of injury. Lab testing of materials would be an important step in the design process; however, real-world testing is always essential in order to ensure that products function as intended (Mattson \& Wood, 2014). All PPE products designed for wealthy markets must conform to various government and industry determined standards to ensure they meet the requirement of functionality and actually prevent injury. In addition to various industry standards, the American National Standards Institute (ANSI), ASTM International, International Safety Equipment Association (ISEA), International Organization for Standardization (ISO), UL LLC, and the European Union (EU), are just some of the independent organizations that define specific performance standards and testing procedures for PPE sold in western markets. These standards help ensure that users are sufficiently protected from injury during specific 
activities, and discourage manufacturers from making false claims about the performance of their products. There exist a multitude of standards that cover PPE products for a wide variety of applications, from respirators, to hard hats, boots, safety glasses, hearing protection, chemical and heat resistance, cut protection, and more. These standards set specific requirements and testing procedures. For example, ASTM standard F1414 describes the methods required for testing cut resistance of chainsaw lower body protective clothing (ASTM, 2019). Since standards like these are developed for PPE products marketed in the West for users in western work environments, they do not necessarily apply to the unique work activities of workers in developing contexts -- like swinging machetes, which is quite rare in the United States and Europe.

Theoretically, the existing standards that may be applicable to MPPE relate to cut resistance, most commonly used for hand and arm protective products like gloves and sleeves. After all, the machete is primarily a cutting tool. These existing cutresistant products are used in work activities that involve manipulating or operating heavy machinery or tools that may have sharp edges, sorting garbage or recycling, in kitchens, etc. They are designed to offer protection against cuts from extremely sharp objects, and the standards and testing procedures reflect this requirement. The most well-developed, and currently the most widely used standard for cut resistance is ANSI/ISEA 105-2016. It is a comprehensive standard for work gloves that covers puncture, needle-poke, abrasion, chemical, ignition, heat, and vibration resistance in addition to cut resistance (ISEA, 2016). Each attribute has a specific test procedure, which in the case of cut resistance, results in a nine-level rating (A1 - A9), depending on the performance of the material. The required ASTM F2992-15 cutresistance test procedure (see Fig. 4.1.1.1) measures the force required to cut through the material at a single point with a razor blade moving a distance of 0.020 m (DuPont, 2007). Level A1 materials can withstand a cutting force of $0.200-0.499$ 
kgf (1.96 - $4.89 \mathrm{~N})$, while level A9 materials withstand >6.00 kgf (>58.8 N) cutting force with $0.02 \mathrm{~m}$ of blade movement (Magid, 2016).

\section{$\underline{\text { TDM Test }}$}
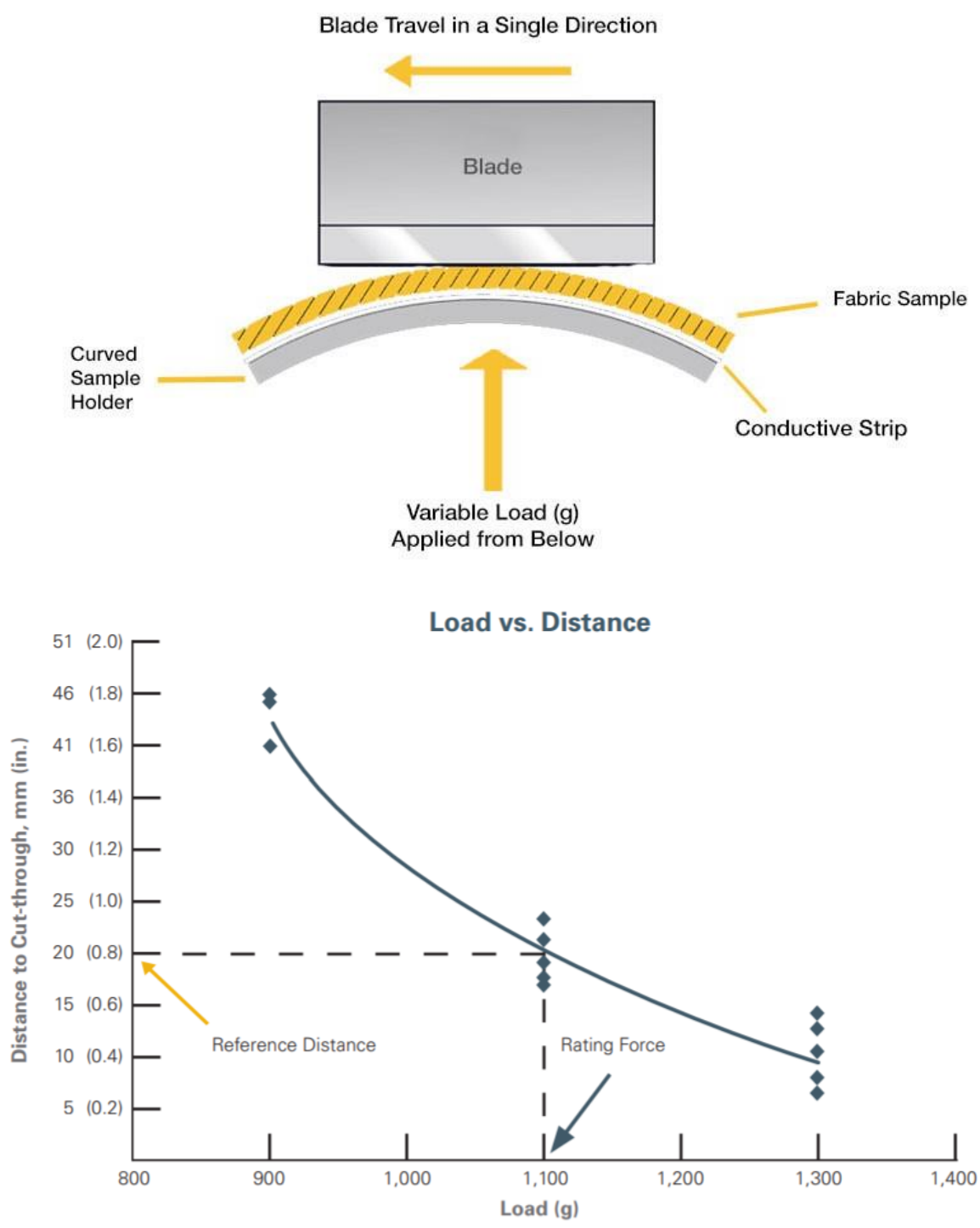

Figure 4.1.1.1. Top: A graphical representation of the TDM test used to measure the cut resistance of materials in the ASTM F2992-15 test procedure ("Cut levels", 2017). Bottom: The analysis of TDM test results showing how applied loads and distances of blade movement vary in each test to obtain a standard cut-through force value at $0.020 \mathrm{~m}$ (DuPont, 2007). 
Though the ANSI/ISEA 105-2016 cut resistance standard could be an indicator of which materials may be good candidates for use in MPPE, the way the ASTM F299215 test is conducted is not necessarily applicable to all machete accident scenarios. The test involves a sharp blade that is carefully placed and drawn across the material, and the highest level, A9, only requires resistance to a cutting force of $>58.8 \mathrm{~N}$, which does not necessarily correspond to the commonly reported accident scenario where a sharp machete blade strikes the body nearly perpendicularly at high speed and likely with much greater force. During interviews, there was a report of a severe leg injury in this scenario where the machete blade entered deeply into the knee without even cutting through the overlying thin polyester pants, indicating that the blade was not necessarily very sharp but that the blunt force of impact allowed it to break through the skin and pull the pants material in with it. Therefore, it is likely that some level of rigidity and blunt impact protection may be necessary for full machete protection. ANSI/ISEA 138-2019 is the most stringent standard for impact resistance in work gloves, with a test that involves dropping a $2.5 \mathrm{~kg}$ steel ball with energy of $5 \mathrm{~J}(0.204 \mathrm{~m})$ onto different parts of the glove and measuring force transferred to the material underneath it (ISEA, 2019b). Gloves that meet these standards typically use thermoplastic elastomer (TPE) pads attached to the back side (see Fig. 4.1.1.2). However, it is unclear how the impact energy and pressure of the standard test compares to a real-world machete accident scenario or whether the TPE material is appropriate for the MPPE application. 


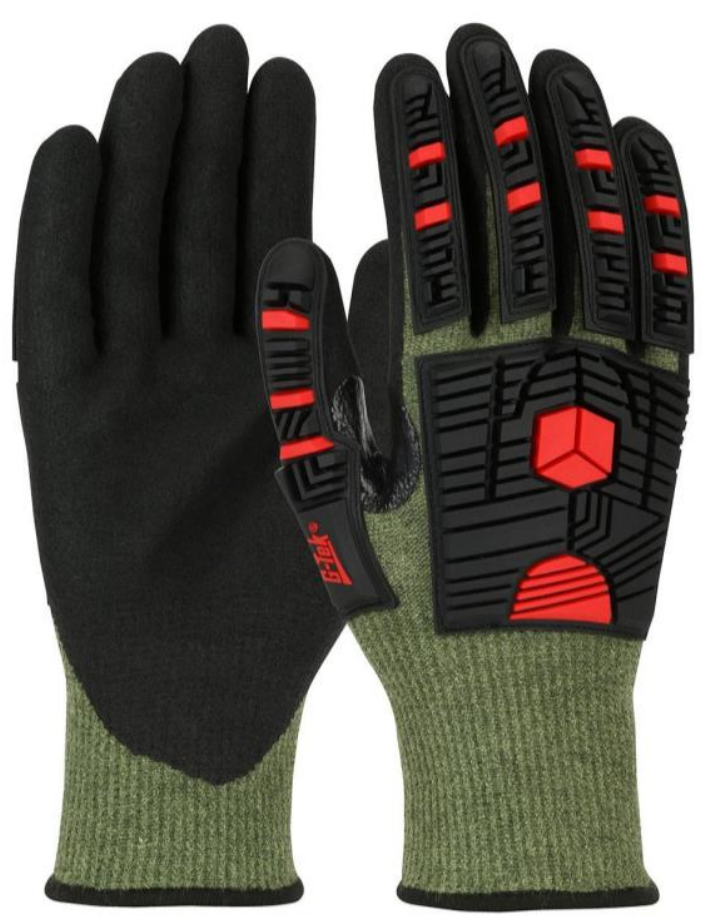

Figure 4.1.1.2. An example of a commercial cut- and impact-resistant work glove available in the United States, made from a proprietary blended synthetic and steel wire knit fabric, along with impact protecting TPE pads on the back, and a grip coating on the palm. This particular glove is rated ANSI/ISEA 105-16 cut level A9, the highest level for cut protection and level 1 for back of the hand impact protection (PIP, 2019).

Clearly, in order to develop functional MPPE products, there is a need for a new standard and test procedures specifically for machete injury protection. This test standard needs to approximate real-world accident scenarios and incorporate a perpendicular impact with a machete blade. As a preliminary investigation into understanding the applicability of existing standards to machete PPE and eventually developing a new standard for MPPE, I conducted a set of basic experiments using materials of known ANSI/ISEA cut resistance and impact resistance ratings. These experiments involved a perpendicular impact of a sharpened machete blade on a test material sitting atop a piece of closed cell foam approximating human tissue. Results strongly suggest that cut resistance alone is not sufficient protection from perpendicular machete impact, since one material (the woven Kevlar fabric) 
repeatedly proved uncuttable in the tests but still allowed the machete blade to cleave through the foam and even cause damage to the harder underlying rubber below it. This corroborates anecdotal evidence gathered during interviews of an injury where the machete inflicted a serious laceration to the leg without even cutting the overlying fabric of the pants, and shows that some level of rigidity is required in the material to prevent the blade from pushing it down through the soft human tissue underneath. Even the addition of impact resistant TPE pads do not appear to offer any additional protection. However, this does not mean that the types of materials used in these cut-resistant gloves could not be used to protect the legs and feet from a perpendicular machete impact. Gloves are required to allow for a high level of dexterity, limiting the weight and rigidity of the material. All the tested gloves were thin and pliable around the palm and fingers, and despite being cut-resistant, offered little protection against a high-energy blade impact. Since dexterity is much less important for the legs and feet where perpendicular impact is most likely, heavier fabrics of the same types of high-tech fibers, made with more rigid stitch patterns, could potentially be used for this application. In fact, two stacked layers of glove material rated A6 and above appear to reliably offer adequate protection based on my experiment, where neither the test materials nor the foam they were protecting were cut or torn, proving that a simply thicker fabric can have the necessary rigidity.

In addition to the perpendicular impact test, I also experimentally reproduced a slipand-fall accident to test protection against this common hand injury scenario. The test material was doubled over the blade, gripped with moderate pressure, and pulled down along the blade for $0.5 \mathrm{~m}$. Test materials rated cut resistance level A4 and below did not offer significant protection; however, materials rated A6 and above could not be cut at all in this manner, meaning that these commercially available gloves could serve as functional MPPE products for hand protection. Full details and results from these experiments can be found in Appendix A. 
The experimental results indicate that two different standard tests should be developed as part of a new MPPE safety standard: a perpendicular impact test for leg and foot protection products, where this type of accident is more likely, and a cut test for hand protection products, similar to the existing ASTM F2992-15 test. These new MPPE tests should provide a simple pass/fail result, similar to the ASTM F1414 chainsaw leg protection test, rather than tiered ratings as in ANSI/ISEA 105 that is designed to cover a wide range of products for many different applications.

Though standards are necessary, developing markets like Panama pose unique challenges to ensuring the authenticity of PPE products and enforcement of those standards. Since there is high consumer pressure for affordability in this and other BoP markets, and an underdeveloped regulatory environment (Ceschin \& Gaziulusoy, 2016), in addition to customers with a low education and literacy levels, there is a high risk that users' safety could be endangered by purchasing fraudulent products that don't function as advertised. This problem can be mitigated through a strong business model that incorporates effective customer education with clear packaging design (Hasan \& Lowe, 2017), as well as an investigation of existing laws, and the identification and close collaboration with key government officials to ensure their enforcement (Mattson \& Wood, 2014).

\subsubsection{Usability}

Even if a product is functional, to be effective it needs to be easy to use, difficult to misuse, and fit into everyday life with few behavioral adaptations that would inhibit adoption. In conversations during household interviews, the primary factor in usability seems to be comfort. MPPE products will be worn for hours on end in harsh, hot, humid, and often wet conditions while users exert themselves physically. It is essential that the user rarely if ever feels the desire to remove the MPPE for reasons of discomfort leaving them vulnerable to injury. However, they also need to 
be easy and quick to put on so that it fits seamlessly into the regular routine of preparing for work. In the case of leg protection, the product needs to fit comfortably inside of the tall PVC rubber boots people wear out to the farm. It needs to be soft to prevent chafing and also breathable to prevent excessive sweating and the skin problems that can cause. Fungal infections of the feet are already a problem due to the moist environment, unbreathable PVC boots and the fact that many people do not use socks. The product at the very least should not exacerbate this problem. Since the knee needs to be fully covered, the product must bend well and not inhibit movement, but should be secured well above the knee so it is not prone to slipping down. One conversation during household interviews illuminated the importance of comfort — decades ago, a man had once attempted to use a cut-open PVC pipe tied to his shin as a form of homemade MPPE, but found it too uncomfortable and quickly removed it, preferring to risk working without any leg protection.

Hand protection should not be too bulky and allow for the necessary dexterity to properly grip the machete without causing fatigue. A special coating should be used on the palm and fingers to increase grip, because the molded plastic handle of the machete is slippery. Many people already use a knife or file to rough up the handle of new machetes before use for this reason. Grip is a critical aspect of safety protection because many accidents occur when the machete unexpectedly slips from the hand.

Sizing is a key aspect of comfort and usability, since people do not have the means to risk purchasing a product that does not fit. More detailed information needs to be collected on people's physical measurements to get an idea of the distribution of sizes, since people tend to be significantly smaller than those in western markets, though due to improving health conditions and better nutrition, this difference appears to be narrowing with each generation. These products will be developed 
primarily for men who are most affected by injuries, but interest was expressed about PPE for children both by parents and the children themselves. Women may also be interested, because though they are injured less frequently, they do use machetes on a daily basis. Sizes need to be developed accordingly. A forgiving material like knitted fabric would allow for more flexibility in sizing, otherwise the products should be custom manufactured for each user.

In addition to usability during work, the MPPE product also needs to be easy to maintain. It should be simple to clean and remove stains, and not have any special washing requirements - the way clothes are washed is generally quite harsh. It should also dry quickly so that people don't leave home unprotected while their MPPE is hanging on the clothesline in the humid, often cloudy and rainy climate.

\subsubsection{Durability}

Successful machete PPE products must be durable, especially given the harsh environmental conditions and the heavy use they will receive. This attribute illuminates the insufficiency of lab testing and the necessity for long-term field testing. Due to the unique local tropical climate and environment, many durability problems that engineers rarely encounter in more familiar dry, temperate climates could manifest. Fungus and mold are omnipresent and insidious problems in this climate that especially affect fabrics, causing permanent stains, smells, and sometimes even deterioration. High humidity also causes oxidation even to highly resistant materials like galvanized steel and even some alloys of stainless steel over time. Insects and other pests are another problem many western engineers may not account for -- with people's homes offering minimal barrier or distinction between "indoors" and "outdoors". Ants, moths, roaches, wasps, and mice frequently destroy clothing and other possessions stored in homes. 
Overall, MPPE products need to be designed like pieces of professional-grade work equipment in terms of durability. It will be used daily for hours at a time, and is not a casual consumer product designed to be used only occasionally. In addition to being resistant to damage by machetes, it needs to stand up to the abrasions of daily use, like rubbing inside of boots, and against thorns, the earth, and other rough objects. It could be useful to study ASTM test standards D3884 and D3389 for abrasion resistance in textile fabrics and coated fabrics, respectively, and the ANSI/ISEA 105-2016 ratings for abrasion resistance (0 - 6 scale) to identify candidates for appropriate materials (ISEA, 2019a). However, long-term field testing will ultimately be more demonstrative. These products must be designed to be abused, because that is the nature of life and work in this target market. Since people in Quebrada Plátano currently rarely use any type of PPE, and the products will likely be a significant extra investment for them, long-term durability will strongly determine their reputation. According to one household interview, any product must last at least a year of heavy use to be worth buying. However, other interviews revealed a sentiment that a more expensive, special product designed to be tough enough to be resistant to machete injuries would have even higher expectations for durability than other widely used products like regular clothes, boots, or backpacks. The longer these products last, the less likely it is that a person will get caught in an accident without them.

\subsubsection{Repairability}

Every product has a limited lifetime, and no matter how durable, will eventually wear out. For customers living in poverty, this is a daily struggle since damaged and worn-out products cannot easily be replaced, and imported technology is often quickly discarded if replacement parts are not locally available or the skills and technology to repair them do not exist locally. Being accustomed to poverty and resource limitations however, people in Quebrada Plátano prove themselves to be 
champions of creative repairs and revival of seemingly destroyed clothing, tools, and household items. Torn rubber boots are stitched together with near surgical precision, pants are repeatedly patched with fabric scraps for over a decade, new tool handles are quickly whittled from a nearby stick, and broken radios miraculously revived with a small nail, steel wire, and some adhesive.

A business model that allows for local availability of materials and even local manufacture is a fundamental way to ensure a high level of repairability of products. It means local people will have the means and the skills to make repairs. However, the range of skills available in this community is limited, and access to technology is restricted to the most basic tools. Some of the key skills that exist in the community include felling trees and milling lumber with chainsaws, construction of wooden structures, horseback riding, making traditional crafts, and clothes making. Several women and men in the community are skilled seamstresses and tailors who use treadle sewing machines to make dresses, skirts, and men's pants from fabric purchased in town, and typically do business only with people in the community or in the immediate local area. For this reason, MPPE products should use fabric-like materials that would be sewable in the same machines that people already own with few modifications. In conversations during household interviews, I identified two male tailors who showed an interest in working with the woven Kevlar cut-resistant fabric I showed them, and saw it as a potential business opportunity. One barrier for them is that a special shear tool is required to cut durable cutresistant fabrics, and is not locally available. Although the tailors felt confident in making a leg protector or sock-like product, because of their experience in pants making, they did not feel confident about making a consistent glove that would be comfortable and ergonomic. This problem could be solved by training, and development of patterns they could use as guides while sewing. Even if local manufacture does not prove viable in the long-term for all products, it will still be important to make sure tools and materials for repairs are locally available. 


\subsubsection{Sustainability}

All products should be assessed for their environmental impacts, both due to the lifecycle of the product itself, and the role the use of the product plays in shaping users' behavior. Maximizing durability and repairability is a key way to reduce waste, especially in a place with no access to proper solid waste management systems. Anything thrown away often ends up in local streams and rivers or is burned, causing health problems like asthma. Biodegradable or natural materials should be investigated. One possible positive environmental impact of MPPE, in general, is that it can help prevent or slow the shift from organic practices towards using agrichemicals and herbicides. In one conversation, an elderly man said that he now prefers to use herbicides to keep the grass and weeds from growing up around his house because using a machete is too dangerous for him. If using a machete were made safer, it would be less tempting for people to shift towards using potentially dangerous chemical products that have negative health and environmental impacts.

\subsubsection{Affinity}

Affinity refers to how it makes people feel to own a product. High affinity means people feel proud to own it, or that it helps boost their social status amongst others. Research has shown that poor people will practice conspicuous consumption of goods even before all their basic needs are met, if they feel that it boosts their social status -- indicating that social status itself is a basic human need (van Kempen, 2005). Additionally, certain marginalized groups, including indigenous people in Latin America, have been shown to practice this status consumption as a form of compensation for their self-perceived lower social status (van Kempen, 2005). I observed this phenomenon in Quebrada Plátano where people would often spend money on expensive smartphones, or designer brand clothing and shoes, even while they were having trouble feeding their children or sending them to school. 
Although this fact could be used to take advantage of the poor -- marketing products that they do not actually need, and robbing them of resources for nutrition, health, and education (Jaiswal, 2008), it could also be used to help encourage people to purchase new types of beneficial products that are unfamiliar or have a high barrier for adoption. Additional questions need to be asked in future conversations with people in the community to better understand specifically what factors make them feel proud to own certain products, or why they have chosen to buy certain non-essential items.

\subsubsection{Desirability}

Desirability is closely related to affinity -- a product may be fully functional, welldesigned, usable, and durable, but if it doesn't fulfill a person's desires for aesthetics and help boost their social status, it is less likely they will spend precious limited funds to buy and use it. Among designs for BoP markets, there appears to be a tendency for designers not to pay enough attention to aesthetics and ergonomics (Jagtap et al., 2015), with the assumption that users in these markets are looking for purely utilitarian designs and have no preferences for appearance or need for social approval. For any product worn like clothing, local design trends should be considered. In Quebrada Plátano, as in many parts of the world, the younger generations are much more interested in current fashion and design trends, and are especially influenced by popular Puerto Rican Reggaeton musicians and soccer players. These stylistic choices like bright colors, specific logos, or catch phrases could be incorporated into the design and packaging of MPPE. Traditionally, Ngäbe people decorate the borders of clothing with colorful, overlapping triangular patterns called dientes (teeth), which could also be a good aesthetic option for older customers and to bring a traditional touch to a new technology. Of course, these stylistic choices could grow organically if MPPE products were manufactured locally, but local manufacturers would need to be reminded to avoid the trap of purely 
utilitarian designs. Products manufactured elsewhere would require a more careful study of local styles, and would require regular follow-up market research to keep up with changing trends. Price could be an important factor as well, because paradoxically, more expensive goods are often more desirable since they become more "exclusive", and therefore offer a greater boost to social status when purchased (van Kempen, 2005; Whitehead, 2015).

\subsubsection{Affordability}

MPPE will only be an effective solution if the vast majority of people in the target market can afford to buy it. Depending on the operating, manufacturing, and distribution costs of the business, the products may end up too expensive to sustainably sell at affordable, unsubsidized prices. Throughout the design process, affordability must be considered -- whether it is the simplicity of the design, cost of materials, or how the business model will operate. In wealthy markets, manufacture in modern, mechanized facilities is often seen as a cost-saving measure. However, in BoP markets, the benefits of local, low-tech manufacture and the education, training, and jobs it brings, can stimulate the local economy, and can also make distribution simpler and more cost-effective (Mattson \& Wood, 2014). Gathering information regarding willingness to pay for MPPE products through household interviews proved difficult, however, especially without any functional prototype product to demonstrate. Continued work with local counterparts will help ensure that products are affordable enough for widespread adoption in the target market.

\subsection{Summary of Key MPPE Product Design Requirements}

An analysis of key product attributes using the framework developed by Whitehead (2015), in light of my own personal experiences in the local context and with household interviews, starts to build a picture of what MPPE products would look 
like. Due to the types of accidents that occur, it is clear that two distinct products are required for full protection: a leg protector that extends from the toes to just above the knee, and a glove. In order to ensure functionality, a new standard specifically for MPPE needs to be developed that incorporates cut-resistance and impactresistance and a lab-test that approximates real accident scenarios, including slicing and perpendicular impact. The material must be cut-resistant but also have some rigidity to protect against impact, though without sacrificing comfort and ease of movement, especially around the knee. Extensive, long-term, real-world testing is also necessary to ensure usability, comfort and durability. Repairability is improved if the products are made from locally familiar materials like fabrics that can be manufactured or repaired with treadle sewing machines. High-tech knit fabrics made from materials like Kevlar, Dyneema, or blended fibers with steel thread commonly used in currently available commercial PPE products are good candidates, as long as their cost ensures affordability. Aesthetics cannot be ignored and must conform to local trends, including influences from traditional Ngäbe culture and pop culture alike. 


\section{Chapter 5. Viable Business Model Considerations for MPPE}

\subsection{Business Models in the BoP Context}

An effective business model is just as important as a well-designed product, since good ideas and designs won't have an impact unless people buy and use them (Mattson \& Wood, 2014). The co-development of a business model goes hand and hand with the co-design of products. The type of business model, and strategies for manufacturing, distribution, pricing, and marketing will inevitably affect the physical design of the products themselves. In recent years, much attention in the development of BoP enterprises has focused back towards the AT philosophy of hyper-local production, shifting from a view of BoP people as consumers, towards BoP people as producers -- where the focus shifts towards sourcing products from the local market (Ceschin \& Gaziulusoy, 2016). This means that the target area benefits not only from the products themselves, but also from the jobs and development of skills through training that local production can provide. These strategies see people in impoverished markets "as business partners to be empowered, enabled, and involved in the process of business co-invention and cocreation" (Ceschin \& Gaziulusoy, 2016, p. 128) and also to become empowered and self-supporting entrepreneurs rather than dependent on outsiders (Castillo et al., 2012).

Business co-development, besides stimulating the local economy, also has the benefit that local people are those who best understand local needs and desires, ensuring the business model is culturally appropriate (Simanis \& Hart, 2008) and building trust between the enterprise and local communities. People will be more likely to spend their limited money if they know it benefits a local business that they trust (Mattson \& Wood, 2014). However, in many BoP markets skilled workers and 
educated professionals are in highly limited supply, meaning start-up may be more costly and time consuming due to the necessary training and education programs involved. Outsiders need to invest significant time into identifying local talent, which often comes naturally out of the product co-creation and co-design process. This problem can be mitigated by designing products for simple manufacturing techniques, even those that involve no electricity and human powered machines and tools. Engineers, often accustomed to design with few limitations and tempted to come up with solutions that involve cutting edge technologies, need to understand that using local people and resources for production is more sustainable and helps reduce poverty even more than products themselves (Pansera \& Sarkar, 2016).

Different funding options need to be investigated as well, with business sustainability in mind. Relying on philanthropy, grants, or other subsidies can be a necessary source of start-up funding, but could cause unsustainable local dependency and artificially inflate the market. A fundamental part of any BoP business model is a plan to eventually end outside market subsidies entirely (Mattson \& Wood, 2014).

In the case of Quebrada Plátano, a strong case can be made for local manufacture of MPPE products, in addition to a network of local distributors and marketers. Although the likely required raw materials are not currently available in the area, it would be possible to develop relationships with local retailers in the developed towns of Changuinola, Almirante, and Chiriquí Grande, made up of a relatively tight knit group of Chinese-Panamanian entrepreneurs, in order to make these materials available -- just as they sell bulk fabrics that Ngäbe subsistence farmers purchase to make regular clothing. The area also counts on a number of buhoneros, traveling salesmen, often Ngäbe, that carry in household products and clothing on their backs up to 3-4 hours from the nearest road. The buhoneros enjoy a good 
reputation amongst local people for selling products at affordable prices in areas where people must otherwise expend significant time and resources travelling to towns to buy clothes household supplies. Building relationships with buhoneros could be a key aspect to the distribution and marketing network in the area. The fact that almost all small rural communities in Bocas del Toro have at least one person who owns a treadle sewing machine and already makes clothes means that local manufacture is theoretically possible if tailors can be convinced a market exists and that it is a good business opportunity to manufacture MPPE. These local tailors could use the walking buhoneros either to get supplies of raw materials, or to distribute their finished products. They can also continue to work directly with customers within their communities or in the immediate local area.

Tailors will face several obstacles to starting up this business. The first is the initial expense of raw materials, and new equipment, namely the special shears required to cut durable cut-resistant fabrics. These investments may need to be subsidized until their business gains steam. Next, the new skills required to manufacture these products, especially gloves, will require some training which would be aided by the development of sewing aids like patterns. Existing protective work glove products may already be suitable for MPPE purposes, so importation of this more difficult-tomanufacture product should still be considered. Finally, since most tailors have at best a primary school education, and limited business knowledge and money management skills, they could greatly benefit from a basic business education program to ensure sustainability of the enterprise. All training and education programs should have a "training of trainers" model with the eventual goal of training existing local participants to begin leading the programs so that outside experts eventually become unnecessary.

One disadvantage of local manufacture in this context is the difficulty in constraining materials to be used only for their intended purpose, because people 
have a demonstrated talent for invention and improvisation. Household interviews revealed an interest amongst men and women for using the exotic Kevlar fabric to make fancy backpacks or ultra-durable kras for carrying cargo. Although there is nothing inherently wrong with their ingenuity, this appeared to be an example of "status consumption" rather than a genuine need for a functional material for carrying cargo, which they already have. It is possible that this desire for social status could trump the perceived need for protection from machete injuries, and that materials, which could be subsidized, may be misused for unintended purposes.

One of my failed projects in Quebrada Plátano is a simple example of a similar phenomenon. I taught 12 families how to make a special bucket-like container designed for treating their drinking water at home with chlorine bleach. After the lesson, each family got to keep the special bucket along with a small bottle of chlorine bleach. Subsequent follow-up visits, up to a year after the lessons, showed that none of the 12 families continued using the bucket for water treatment, and instead were using them for doing laundry or for dry storage. Many families later indicated that they were actually only interested in the bucket for these purposes from the start, and that they had no interest in treating their water. This illustrates an important lesson -- people will use a product or material for whatever purpose they find most suitable, regardless of the intentions of the designer. Significant time must be invested for education and training to avoid misuse.

\subsection{Affordability and Price Considerations}

Pricing and affordability are key factors of business sustainability. Efforts must be made during the co-design and co-business development processes to ensure that customers will be able to afford products when they come to market. Flexible payment options can also help those who have unstable or unpredictable income 
(Mattson \& Wood, 2014), as is the case in Quebrada Plátano, either through payment plans or non-traditional payments like trades for goods or services. Studying the types of transactions that happen locally can lead to these types of solutions, for example, the fact that many outstanding debts are settled on dates when welfare checks are paid. However, in some markets, consumers simply may lack the resources to be able to purchase the product after all attempts have been made to reduce prices. In these cases, it may be more useful to focus on solving other, even more basic problems people face, or attempt to tackle the problem through traditional political or governmental solutions (Jaiswal, 2008).

Pricing and affordability need to be explored in collaboration with the final users to assess what they are willing to pay (Castillo et al., 2012). In this case, I had difficulty during household interviews in encouraging people to honestly suggest a price they would pay for machete PPE products, with many people naming very low prices or refusing to name one at all. Suggested prices ranged from $\$ 5$ - $\$ 60$, with several people stating they would only use MPPE if it were available for free. I suspect this is due to a suspicion that naming a price would undermine their chances of receiving free or heavily subsidized products in the future. To address this issue, a more systematic approach to market research and willingness to pay (WTP) methodology could be used in the future, like the Becker-DeGroot-Marschak method (BDM). In this method, respondents are asked to state a reservation price for a product within a given range. A price is then randomly generated within that range, and if their stated reservation price is lower than the generated price, they receive their reservation price as cash. If their stated reservation price is higher, they are given the opportunity to purchase the product at their stated price. This gives participants an incentive to make their true reservation price known; it is to their own disadvantage to exaggerate their willingness to pay or state a low reservation price (van Kempen, 2005). This method, however, requires that at least a prototype product already exist. Surveys that more carefully monitor people's income and 
expenditures, as well as direct questions about certain essential and non-essential purchases could be illuminating in the early stages of product development. It is important to keep in mind that subsidized or deliberately deflated pricing may be damaging to sales, because a higher price can suggest to potential buyers that the product is of high quality, and increase desirability of products by boosting customers' social status (van Kempen, 2005). Detailed understanding of the context and target market is, as always, important in this regard.

\subsection{Marketing and Advertising}

Even a well-designed, functional, usable, durable, desirable, and affordable product will not be used if people in the target market do not know it exists, know about the benefits it delivers, or ultimately have a strong desire to purchase it. Marketing and advertising strategy cannot be ignored even in resource-poor BoP markets. Selling products in these markets can be made especially difficult since resource-poor individuals are extremely risk averse (Mattson \& Wood, 2014).

People are often hesitant to use or buy anything until they see that it works with their own eyes (Mattson \& Wood, 2014), and Ngäbe people living in rural communities who are culturally isolated and generally distrustful of outsiders and skeptical of new technologies are an example of this phenomenon. During household interviews, most people quickly requested a demonstration to prove that the woven Kevlar fabric I showed them was actually as cut-resistant as I claimed. Even after doing a demonstration myself, some people still did not seem interested until I told them that their neighbor also was unable to cut through it, which led them to ask if they could try it for themselves. Anyone seen with a new product, whether it is a different brand of boot, a new tape measure, or hair pomade, is subject to much intrigue and probing conversation into the use, function, level of quality, and price from their neighbors and family. Though a wide selection of 
products is available for purchase in town, the rural Ngäbe people tend to be conservative buyers, with people in small communities throughout the region tending to buy the same sets of products -- rarely spending precious funds on those that are unfamiliar and untested. For this reason, marketing and distribution of MPPE needs to have a hyper-local emphasis, facilitating word-of-mouth communication through existing channels like local tailors and the buhoneros by providing them sales training and sales materials. A creative payment program that gives incentives for existing owners and early adopters to convince others to buy could also be a good strategy.

The product design and packaging are also important to create a desirable image of the product. As mentioned in Section 4.1.7, the product must conform to local aesthetic styles and current trends, which could either be geared towards younger people, for example with pop music or sports (soccer) related designs, or to a more traditional market with Ngäbe dientes styles. It would be essential to give local manufacturers the encouragement and the means to create these types of aesthetics, providing materials of certain colors, design suggestions, and patterns. Although many resource-poor people spend money on non-essential products to boost their social status, often to the detriment of failing to meet their basic needs (van Kempen, 2005), a phenomenon I observed in this context as well, status consumption can also be used to help market necessary products designed to reduce poverty if they are designed with aesthetics and desirability in mind.

Education levels in rural Ngäbe communities like Quebrada Plátano are generally low; however, basic literacy is widespread. In low-education or low-literacy markets, customers are often confused by packaging or fooled by products that only appear to meet their needs, without reading the fine print (Hasan \& Lowe, 2017). These customers often rely on younger relatives for help, and certain visual cues like products or packaging with distinctive colors, logos, and symbols are key to 
conveying important information to potential buyers. Distinctive symbols can also help customers avoid fraudulent products that make false claims. Raw materials supplied to local manufacturers of MPPE would need to be easily recognizable as authentic, and manufacturers could use distinctive symbols to prove to users that the product meets safety standards. In the end, people's insistence on testing a product themselves will mostly prevent the proliferation of impostor MPPE products. 


\section{Chapter 6. Conclusion}

Through the lessons of the Appropriate Technology (AT) philosophy of designing creative, highly practical, culturally appropriate technology with a hyper-local focus to meet people's most basic needs, and Bottom of the Pyramid (BoP) business models that seek to bring the world's poor into the mainstream economy through co-design and co-development of products, services and businesses, in conjunction with years of personal experience living and working with Ngäbe subsistence farmers in Bocas del Toro, Panama, where I developed strong empathy, deep personal connections, and a profound understanding of the daily lives and challenges people face, and through a series of household interviews, I have developed a theoretical framework for the design and development of personal protective equipment for workers using machetes (MPPE) that would reduce the health and financial impacts due to the ubiquitous problem of machete injuries that can cause pressure on families and contributes to hunger, prevents children from receiving an education, and causes permanent disabilities. These MPPE products would include leg protection that extends from just above the knee down to the toes, like a tall sock, as well as hand protection in the form of a glove. Both products would have culturally appropriate aesthetics, and to maximize functionality and comfort, would likely be made from high-tech blended synthetic and/or steel knit fabrics and plastic materials used in PPE products for other applications currently available in western markets, and if properly designed, could be manufactured, distributed, and marketed locally using available technology, skills, and channels in order to ensure the highest impact on reducing poverty through a viable social enterprise managed primarily by local people. 


\section{References}

ASTM (2019). Standard Test Method for Measurement of Cut Resistance to Chainsaw in Lower Body (Legs) Protective Clothing. Retrieved from https://www.astm.org/Standards/F1414.htm

Ben Letaifa, S., \& Reynoso J. (2015). Toward a service ecosystem perspective at the base of the pyramid. Journal of Service Management, 26(5), 684-705. doi:10.1108/JOSM-04-2015-0133

Castillo, L., Diehl, J. C., \& Brezet H. (2012, January). Design Considerations for Base of the Pyramid (BoP) Projects. Paper presented at the Cumulus Conference, Helsinki, 2012.

Ceschin, F., \& Gaziulusoy, I. (2016). Evolution of design for sustainability: From product design to design for system innovations and transitions. Design Studies, 47, 118-163. doi:10.1016/j.destud.2016.09.002

Cut levels for hand protection. Do you understand the changes? (2017) Retrieved on November 10, 2019, from https://www.nusafe.co.uk/cut-levels-handprotection-understand-changes/

Dunn, P. D. (1978). Appropriate technology: Technology with a human face. London: Macmillan Press Ltd.

DuPont (2007). DuPont Kevlar: The science of cut protection [PDF file]. Retrieved from https://www.dupont.com/content/dam/dupont/products-andservices/personal-protective-equipment/cutprotection/documents/DPT_Kevlar_Cut_Protection_Testing.pdf

Hasan, M. R., Lowe, B., \& Rahman, M. (2017). Visual cues and innovation adoption among bottom of the pyramid consumers. Qualitative Market Research, 20(2), 147-157. doi:10.1108/QMR-04-2015-0032 
Hayes, R. A. (2017). Human Centered Design of an Open-Drum, Treadle Thresher for Quinoa Farmers in the Andes of Northern Peru (Master's report). Michigan Technological University.

IDEO (2015). Field Guide to Human Centered Design. Retrieved from https://www.designkit.org/

IMF, World Economic Outlook Database (2019). Retrieved November 25, 2019, from https://www.imf.org/external/pubs/ft/weo/2019/01/weodata/index.aspx

INEC, República de Panamá (2010). Diagnóstico de la población indígena en Panamá con base en los censos de población y vivienda 2010 [PDF file]. Retrieved from http://www.inec.gob.pa/archivos/P6571INDIGENA_FINAL_FINAL.pdf

INEC, República de Panamá (2019). Panamá en cifras - años 2013-2017: Resumen [PDF file]. Retrieved from http://inec.gob.pa/archivos/P9361 pcresumen.pdf

ISEA (2016). ANSI/ISEA 105-2016 Hand Protection Classification. Retrieved from https://safetyequipment.org/standard/ansiisea-105-2016/

ISEA (2019a). ANSI/ISEA 105-2016 clarification [PDF file]. Retrieved from https://safetyequipment.org/wp-content/uploads/2016/02/Clarification-ANSIISEA-105-2016-abrasion-testing-gram-load.pdf

ISEA (2019b). ANSI/ISEA 138-2019 American National Standard for Performance and Classification for Impact-Resistant Gloves. Retrieved from https://safetyequipment.org/ansi-isea-138-2019/

Jagtap, S., Larsson, A., Warell, A., Santhanakrishnan, D., \& Jagtap, S. (2015). Design for the BOP and the TOP: Requirements handling behaviour of designers. In A. Chakrabarti (Ed.), [Host publication title missing] (pp. 375-385). Springer. doi:10.1007/978-81-322-2229-3_17

Jaiswal, A.K. (2008). The Fortune at the Bottom or the Middle of the Pyramid? Innovations, 3(1), 85-100. doi:10.1162/itgg.2008.3.1.85 
Lipson, C. (2005). How to write a BA thesis. Chicago, IL: The University of Chicago Press.

Magid (2016). Guide to the new ANSI cut levels: Updated cut resistance standards [PDF file]. Retrieved from https://www.magidglove.com/assets/item/docum ent/Guide_to_the_New_ANSI_Cut_Levels_-_Magid.pdf

Mattson, C. A., \& Wood A. E. (2014). Nine Principles for Design for the Developing World as Derived From the Engineering Literature. Journal of Mechanical Design, 136(12), 121403. doi:10.1115/1.4027984

MEF, República de Panamá (2018). Índice de pobreza multidimensional de Panamá 2018 [PDF file]. Retrieved from https://www.mef.gob.pa/wpcontent/uploads/2018/09/Informe-del-\%C3\%8Dndice-de-PobrezaMultidimensional-de-Panam\%C3\%A1-2018.pdf

OnTheWorldMap.com (n.d.) Large detailed map of Panama with cities and towns. Retrieved on November 2, 2019, from http://ontheworldmap.com/ panama/large-detailed-map-of-panama-with-cities-and-towns.html

Pansera, M., \& Sarkar, S. (2016). Crafting Sustainable Development Solutions: Frugal Innovations of Grassroots Entrepreneurs. Sustainability, 8(1), 51. doi:10.3390/su8010051

PIP, 2019. Protective Industrial Products. Retrieved on November 11, 2019, from https://us.pipglobal.com/en/products/?scID=2560\&ccID=11570\&sID=28349\& ssID $=80420 \& p \mid D=91319$

Polak, P. (2008). Out of poverty: What works when traditional approaches fail. San Francisco, CA: Berrett-Koehler Publishers, Inc.

Prahalad, C. K., \& Hart, S. L. (2002). The fortune at the bottom of the pyramid. Retrieved from https://www.strategy-business.com/article/11518

Simanis, E., \& Hart, S.L. (2008), The Base of the Pyramid Protocol: Toward Next Generation BoP Strategy (2nd ed.). Cornell University, Ithaca, NY. 
van Kempen, L. (2005). Status consumption and poverty in developing countries (Doctoral dissertation). University of Tilburg, The Netherlands.

Whitehead, T. J. (2015). Enhancing new product development in low income economies (Doctoral dissertation). Loughborough University, United Kingdom.

World Bank (2017). GINI index (World Bank estimate). Retrieved November 2, 2019, from https://data.worldbank.org/indicator/SI.POV.GINI

World Bank (2018). GDP per capita: PPP (current international \$). Retrieved November 2, 2019, from https://data.worldbank.org/indicator/NY.GDP.PCAP.PP.CD 


\section{Appendix: Experiments}

I conducted a set of simple experimental tests to determine whether currently available materials and existing performance/testing standards are applicable to MPPE performance, especially whether cut resistance alone is a material property that predicts the level of protection in common machete accident scenarios -namely a perpendicular impact of the blade -- or whether additional rigidity and impact protection is also necessary to prevent severe injury.

\section{A.1 Methods}

I acquired several different commercially available cut-resistant products, either arm sleeves or gloves, ranging in ANSI/ISEA 105-2016 cut protection from level A2 to level A7. Several of the gloves also have an additional ANSI/ISEA 105-2016 back-ofthe-hand impact protection level 1 rating. The products are made of several different materials, including knit Kevlar fiber, knit Dyneema fiber (a newer ultrahigh-molecular-weight polyethylene material), and proprietary fiber blends of Kevlar, Dyneema, other synthetic fibers, and/or steel wire. I also tested the 0.24 $\mathrm{kg} / \mathrm{m}^{2}$ woven Kevlar fabric I demonstrated to people in Quebrada Plátano, which has no known ANSI/ISEA 105-2016 cut resistance rating. With the range of materials tested, I considered the most important variable between the different products to be the rated ANSI/ISEA 105 cut resistance level.

I cut each product into rectangular test sample pieces with a pair of special shears designed for the purpose, and I used the palm and back side of each glove separately. Samples were placed atop a similarly sized piece of $0.011 \mathrm{~m}$ thick closed cell foam to approximate human tissue. The foam was placed atop a larger piece of 
hard, dense rubber flooring material to prevent damage to the machete blade between tests (see Fig A.1.1).

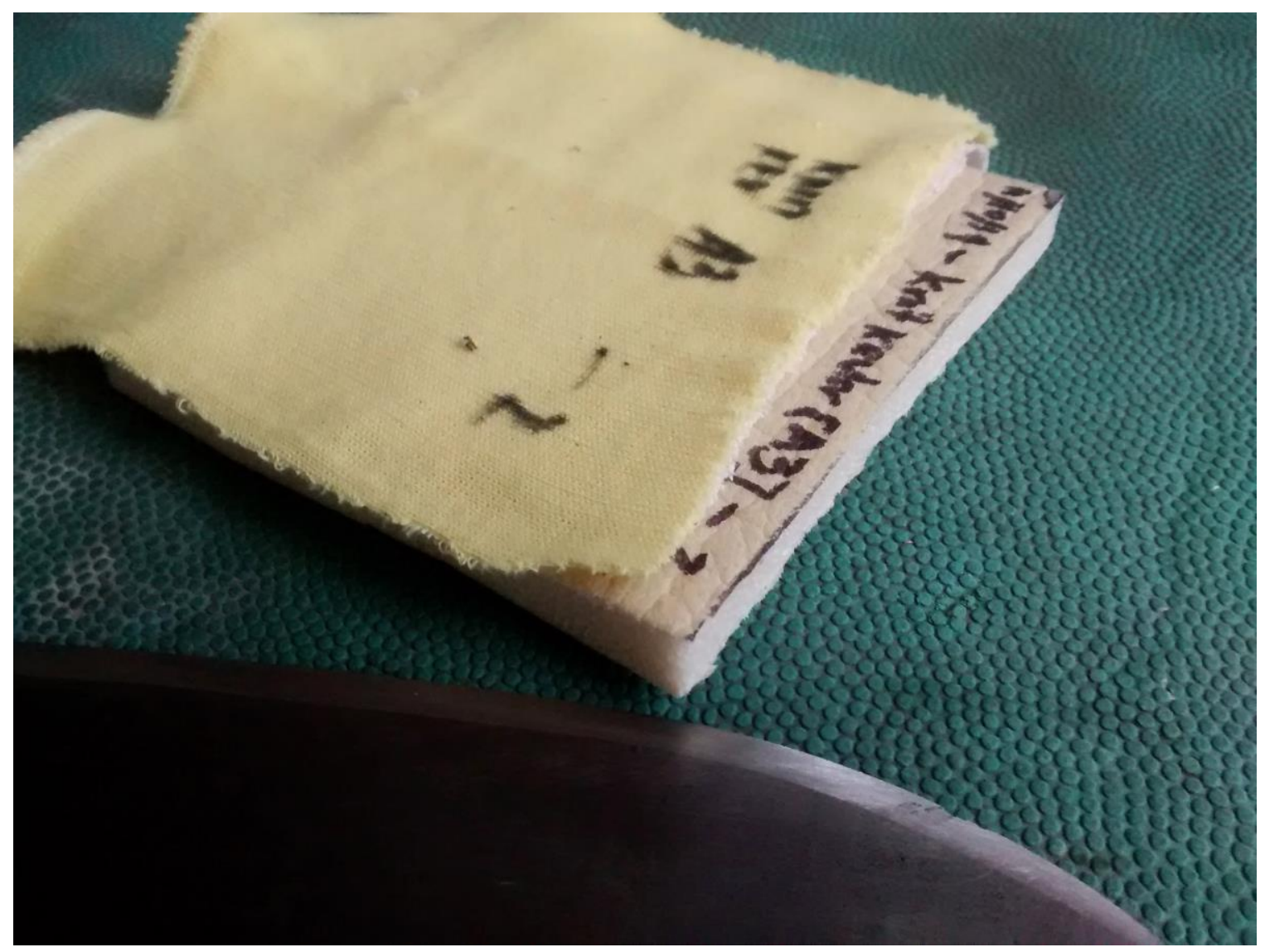

Fig. A.1.1. Experimental setup showing the yellow test material on top, in this case a knit Kevlar fabric rated ANSI/ISEA 105-2016 cut resistance level A3, the white closed cell foam meant to approximate human flesh, and the hard, green rubber material to prevent damage to the machete blade, with the sharpened machete blade below.

I sharpened a 28-inch Imacasa machete, the most commonly used brand and model I observed in Quebrada Plátano, with a standard mill file, using the same method taught to me by people in the community, with an average sharpening angle. Without a more complicated apparatus, it was difficult to maintain a consistent impact energy between each test, which is a significant limitation of the experiment. To maintain as consistent an impact as possible, I kept my knees bent, with my left hand placed on my knee to prevent significant body movement, lifted the machete in my right hand near the side of my head, and swung with moderate force using 
only my arm, striking the target material near the tip of the blade. Two samples of each material were tested, which is probably not sufficient given the variability of impact energy, though further testing was limited by available funding. The blade edge was touched up and deburred with a file between each test.

In addition to the perpendicular impact test, I also simulated a slip and fall hand injury by folding the test material over the blade, gripping it with moderate pressure, and pulling it along most of the length of the blade, or about $0.5 \mathrm{~m}$.

\section{A.2 Results}

The experiments indicate that materials rated ANSI/ISEA 105-2016 cut levels A1 - A3 do not offer any significant protection from a perpendicular machete impact. These materials were easily cut, allowing the machete to slice through the closed cell foam and imbed deeply into the hard rubber underneath, with no noticeable improvement over the control materials. The level A4 sample provided some protection in one test, where the material itself was not cut, but the foam was still cleaved in half from the impact. However, in the second test this material performed similarly to the control. This means the force of impact was likely quite different between those two tests.

Glove materials rated cut resistance levels $A 6$ and $A 7$ seemed to be more tough and difficult to cut through, but ultimately did not offer significantly more protection. Even where the material was almost entirely undamaged, the foam was either entirely or nearly cut through, indicating almost certain severe injury. The addition of impact resistant TPE pads did not seem to offer any additional protection, the machete blade cut right through them, inflicting similar levels of damage to the foam. 
The woven Kevlar fabric I demonstrated to people in Quebrada Plátano has an unknown cut resistance level and was not cut or significantly damaged in any of the tests. However, the machete was able to cut through or damage the foam in every test, even with two layers of this material. The machete either pushed itself, along with the test material, through the foam and even into the hard rubber beneath, or in one test, inflicted a blunt impact on the foam that cleaved it in half (see Fig. A.2.1). This corroborates an anecdotal report of an accident where the machete inflicted a serious laceration to a man's leg without cutting through or damaging his pants. Results from the perpendicular impact experiment are summarized in Table A.2.1.

The most successful tests appear to be when glove materials rated A6 and above were double stacked, making them thicker and more rigid. No significant damage to the foam was observed in these tests, other than a light impression of the blade. These results are a promising sign that the high-tech materials and fibers used in cut-resistant gloves could be used for leg and foot MPPE products, if they are made with thicker, heavier fabrics with different knit or weave patterns.

For the slip-and-fall hand injury experiment, glove materials rated cut resistance level A4 and below were cut through with little effort. Those rated A6 and A7 could not be cut, even after applying the highest level of pressure I felt I could safely exert. Additionally, the proprietary rubbery coating on the palm of the A7 rated glove made the material very difficult to slide along the blade, a property that could offer additional protection -- stopping the hand from sliding down the blade -- reducing the chances of cut-through, and potentially preventing users from falling altogether, if they could safely catch themselves by grabbing onto the machete blade. 


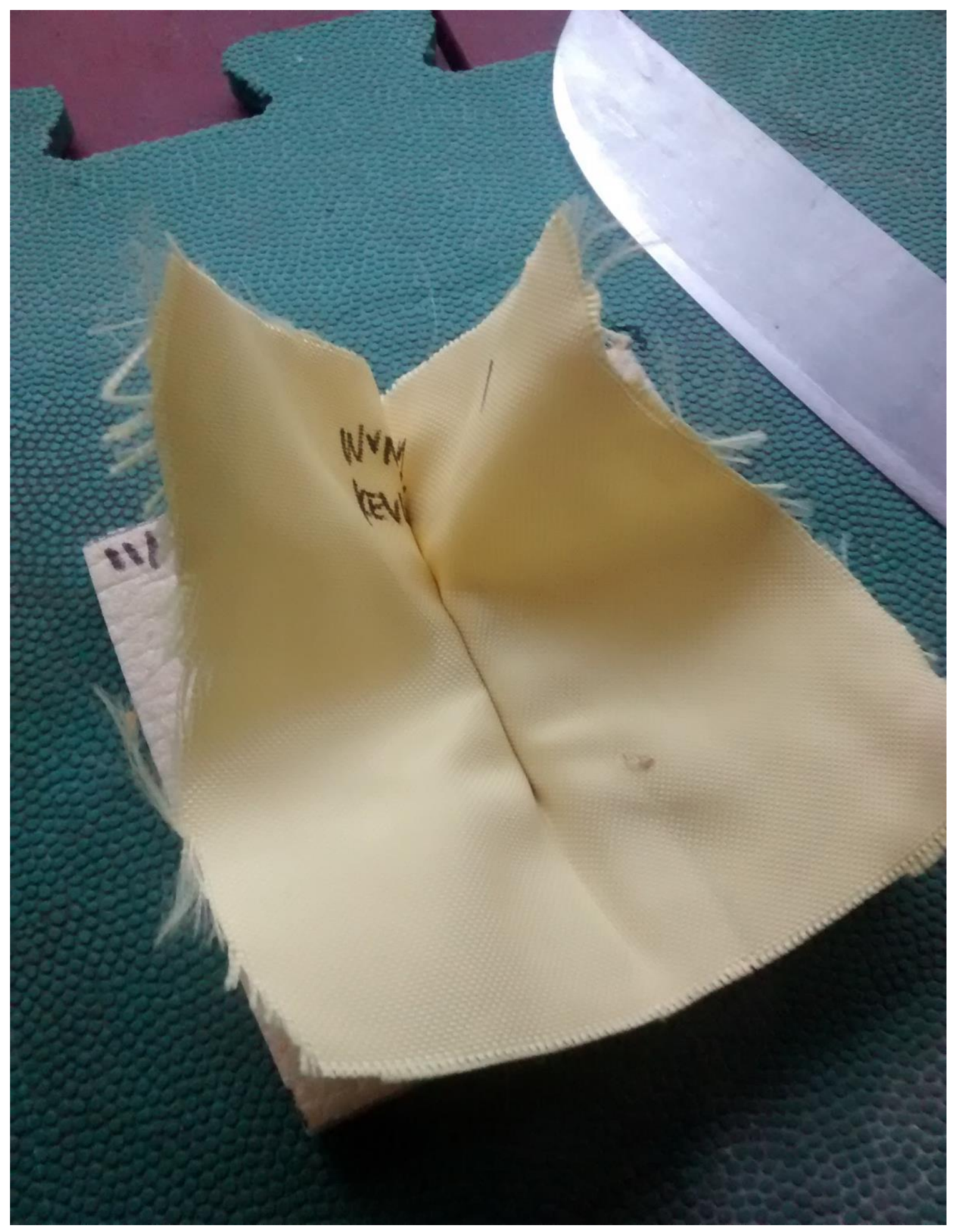

Fig. A.2.1. Result of a test with a single layer of the woven Kevlar fabric with unknown cut resistance rating. The machete pushed the test material, without cutting or damaging it, through the foam and about $3 \mathrm{~mm}$ into the hard rubber layer beneath. 


\begin{tabular}{|c|c|c|c|}
\hline $\begin{array}{l}\text { Test Sample } \\
\text { Material }\end{array}$ & $\begin{array}{l}\text { ANSI/ISEA } \\
105 \text { rating }\end{array}$ & Results - Test 1 & Results - Test 2 \\
\hline $\begin{array}{l}\text { Medium weight } \\
\text { woven cotton - } \\
\text { (control 1) }\end{array}$ & N/A & $\begin{array}{l}\text { Cut through test } \\
\text { material, through } \\
\text { foam, and into dense } \\
\text { underlying rubber }\end{array}$ & $\begin{array}{l}\text { Cut through test } \\
\text { material, through } \\
\text { foam, and into dense } \\
\text { underlying rubber }\end{array}$ \\
\hline $\begin{array}{l}\text { Knit nylon glove } \\
+ \text { nitrile coating } \\
\text { (control } 2 \text { ) }\end{array}$ & N/A & $\begin{array}{l}\text { Cut through test } \\
\text { material, through } \\
\text { foam, and into dense } \\
\text { underlying rubber }\end{array}$ & $\begin{array}{l}\text { Cut through test } \\
\text { material, through } \\
\text { foam, and into dense } \\
\text { underlying rubber }\end{array}$ \\
\hline $\begin{array}{l}\text { Knit nylon glove } \\
+ \text { TPE }\end{array}$ & $\begin{array}{l}\text { Cut - N/A } \\
\text { Impact - L1 }\end{array}$ & $\begin{array}{l}\text { Cut through test } \\
\text { material, through } \\
\text { foam, and into dense } \\
\text { underlying rubber }\end{array}$ & $\begin{array}{l}\text { Cut through test } \\
\text { material, through } \\
\text { foam, and into dense } \\
\text { underlying rubber }\end{array}$ \\
\hline $\begin{array}{l}\text { Knit 'Kevlar' } \\
\text { sleeve }\end{array}$ & $\begin{array}{l}\text { Cut - A2 } \\
\text { Impact - N/A }\end{array}$ & $\begin{array}{l}\text { Cut through test } \\
\text { material, through } \\
\text { foam, and into dense } \\
\text { underlying rubber }\end{array}$ & $\begin{array}{l}\text { Cut through test } \\
\text { material, through } \\
\text { foam, and into dense } \\
\text { underlying rubber }\end{array}$ \\
\hline $\begin{array}{l}\text { Knit 'Kevlar' } \\
\text { glove }\end{array}$ & $\begin{array}{l}\text { Cut - A2 } \\
\text { Impact - N/A }\end{array}$ & $\begin{array}{l}\text { Cut through test } \\
\text { material, through } \\
\text { foam, and into dense } \\
\text { underlying rubber }\end{array}$ & $\begin{array}{l}\text { Cut through test } \\
\text { material, through } \\
\text { foam, and into dense } \\
\text { underlying rubber }\end{array}$ \\
\hline $\begin{array}{l}\text { Knit 'Kevlar' } \\
\text { sleeve }\end{array}$ & $\begin{array}{l}\text { Cut - A3 } \\
\text { Impact - N/A }\end{array}$ & $\begin{array}{l}\text { Cut through test } \\
\text { material, through } \\
\text { foam, and into dense } \\
\text { underlying rubber }\end{array}$ & $\begin{array}{l}\text { Cut through test } \\
\text { material, through } \\
\text { foam, and into dense } \\
\text { underlying rubber }\end{array}$ \\
\hline $\begin{array}{l}\text { Knit 'Kevlar' } \\
\text { glove }\end{array}$ & $\begin{array}{l}\text { Cut - A3 } \\
\text { Impact - N/A }\end{array}$ & $\begin{array}{l}\text { Cut through test } \\
\text { material, through } \\
\text { foam, and into dense } \\
\text { underlying rubber }\end{array}$ & $\begin{array}{l}\text { Cut through test } \\
\text { material, through } \\
\text { foam, and into dense } \\
\text { underlying rubber }\end{array}$ \\
\hline $\begin{array}{l}\text { Knit ‘Dyneema' } \\
\text { sleeve }\end{array}$ & $\begin{array}{l}\text { Cut - A4 } \\
\text { Impact - N/A }\end{array}$ & $\begin{array}{l}\text { Test material not cut, } \\
\text { foam not cut, but } \\
\text { foam cleaves from } \\
\text { underneath indicating } \\
\text { high impact force }\end{array}$ & $\begin{array}{l}\text { Cut through test } \\
\text { material, through } \\
\text { foam, and into dense } \\
\text { underlying rubber }\end{array}$ \\
\hline
\end{tabular}




\begin{tabular}{|c|c|c|c|}
\hline $\begin{array}{l}\text { 'Hex' glove + } \\
\text { polyurethane } \\
\text { coating (palm) }\end{array}$ & $\begin{array}{l}\text { Cut - A6 } \\
\text { Impact - N/A }\end{array}$ & $\begin{array}{l}\text { Test material suffers } \\
\text { minimal damage, } \\
\text { small cut ( } \sim \mathrm{mm}) \text {, } \\
\text { and associated } \sim 5 \mathrm{~mm} \\
\text { through-cut in foam. } \\
\text { Also } 5 \mathrm{~mm} \text { tear in } \\
\text { foam beneath } \\
\text { undamaged test } \\
\text { material (not all the } \\
\text { way through) }\end{array}$ & $\begin{array}{l}\text { Test material suffers } \\
\text { minimal damage, } \\
\text { slightly larger cut ( } 12 \\
\text { mm), however foam } \\
\text { suffers full cut-through } \\
\text { even where test } \\
\text { material is uncut }\end{array}$ \\
\hline ‘Hex’ glove (back) & $\begin{array}{l}\text { Cut - A6 } \\
\text { Impact - N/A }\end{array}$ & $\begin{array}{l}\text { Test material suffers } \\
\text { minimal damage, } \\
\text { small cut ( } 5 \mathrm{~mm}) \text {, } \\
\text { however foam suffers } \\
\text { through-cut over } \\
\text { about half of blade } \\
\text { impact even where } \\
\text { test material is uncut }\end{array}$ & $\begin{array}{l}\text { Test material suffers } \\
\text { minimal damage, small } \\
\text { cut ( } ~ 5 \mathrm{~mm}) \text {, however } \\
\text { foam suffers full } \\
\text { through-cut even } \\
\text { where test material is } \\
\text { uncut }\end{array}$ \\
\hline $\begin{array}{l}\text { ‘PK' glove + } \\
\text { proprietary } \\
\text { coating }\end{array}$ & $\begin{array}{l}\text { Cut - A7 } \\
\text { Impact - N/A }\end{array}$ & $\begin{array}{l}\text { Mostly cut through } \\
\text { test material, with a } \\
\text { few intact threads, cut } \\
\text { through foam, and } \\
\text { into dense underlying } \\
\text { rubber }\end{array}$ & $\begin{array}{l}\text { Mostly cut through test } \\
\text { material, with a few } \\
\text { intact threads, cut } \\
\text { through foam, and into } \\
\text { dense underlying } \\
\text { rubber }\end{array}$ \\
\hline ‘PK' glove + TPE & $\begin{array}{l}\text { Cut - A7 } \\
\text { Impact - L1 }\end{array}$ & $\begin{array}{l}\text { Test material suffers } \\
\text { moderate damage, } \\
\text { several threads } \\
\text { remain intact, } 15 \mathrm{~mm} \\
\text { cut. Foam is cut } \\
\text { through even where } \\
\text { test material is not. }\end{array}$ & $\begin{array}{l}\text { Test material is } \\
\text { completely cut } \\
\text { through. Foam is } \\
\text { completely cut } \\
\text { through, into dense } \\
\text { underlying rubber }\end{array}$ \\
\hline $\begin{array}{l}\text { Woven 'Kevlar' } \\
\text { fabric }(0.24 \\
\left.\mathrm{kg} / \mathrm{m}^{2}\right)\end{array}$ & $\begin{array}{l}\text { Cut - N/A } \\
\text { Impact - N/A }\end{array}$ & $\begin{array}{l}\text { Test material not cut, } \\
\text { but is pushed } \\
\text { completely through } \\
\text { foam cutting into } \\
\text { dense underlying } \\
\text { rubber }\end{array}$ & $\begin{array}{l}\text { Test material not cut, } \\
\text { but is pushed } \\
\text { completely through } \\
\text { foam cutting into } \\
\text { dense underlying } \\
\text { rubber }\end{array}$ \\
\hline
\end{tabular}




\begin{tabular}{|l|l|l|l|}
\hline $\begin{array}{l}\text { Woven 'Kevlar' } \\
\text { fabric (doubled) }\end{array}$ & $\begin{array}{l}\text { Cut - N/A } \\
\text { Impact - N/A }\end{array}$ & $\begin{array}{l}\text { Test material not cut, } \\
\text { but is pushed } \\
\text { completely through } \\
\text { foam cutting into } \\
\text { dense underlying } \\
\text { rubber }\end{array}$ & $\begin{array}{l}\text { Test material not cut, } \\
\text { foam not cut, but } \\
\text { cleaves from } \\
\text { underneath indicating } \\
\text { high impact force }\end{array}$ \\
\hline $\begin{array}{l}\text { 'Hex' glove }+ \\
\text { polyurethane } \\
\text { coating (palm) } \\
\sim \text { Doubled }\end{array}$ & $\begin{array}{l}\text { Cut: N/A } \\
\text { Impact: N/A }\end{array}$ & $\begin{array}{l}\text { Test material is } \\
\text { undamaged other } \\
\text { than an impression at } \\
\text { site of impact, foam } \\
\text { also has an } \\
\text { impression but is not } \\
\text { cut or torn. }\end{array}$ & $\begin{array}{l}\text { Test material is } \\
\text { andamaged other than } \\
\text { impact, foam also has } \\
\text { an impression but is } \\
\text { not cut or torn. }\end{array}$ \\
\hline $\begin{array}{l}\text { 'PK' glove }+ \\
\text { proprietary } \\
\text { coating } \\
\sim \text { Doubled }\end{array}$ & $\begin{array}{l}\text { Cut: N/A } \\
\text { Imp } \times 2)\end{array}$ & $\begin{array}{l}\text { Test material is } \\
\text { undamaged other } \\
\text { than an impression at } \\
\text { site of impact, foam } \\
\text { also has an } \\
\text { impression but is not } \\
\text { cut or torn. }\end{array}$ & $\begin{array}{l}\text { Test material is } \\
\text { undamaged other than } \\
\text { impact, foam also has } \\
\text { an impression but is } \\
\text { not cut or torn. }\end{array}$ \\
\hline
\end{tabular}

Table A.2.1. Summary of results from perpendicular impact experiments. The final two tests, with a double layer of material from gloves rated ANSI/ISEA 105 cut levels $A 6$ and $A 7$ were the only materials that seemed to reliably offer sufficient protection. 